\title{
Are ticks venomous animals?
}

\author{
Alejandro Cabezas-Cruz ${ }^{1,2}$ and James J Valdés ${ }^{3^{*}}$
}

\begin{abstract}
Introduction: As an ecological adaptation venoms have evolved independently in several species of Metazoa. As haematophagous arthropods ticks are mainly considered as ectoparasites due to directly feeding on the skin of animal hosts. Ticks are of major importance since they serve as vectors for several diseases affecting humans and livestock animals. Ticks are rarely considered as venomous animals despite that tick saliva contains several protein families present in venomous taxa and that many Ixodida genera can induce paralysis and other types of toxicoses. Tick saliva was previously proposed as a special kind of venom since tick venom is used for blood feeding that counteracts host defense mechanisms. As a result, the present study provides evidence to reconsider the venomous properties of tick saliva.

Results: Based on our extensive literature mining and in silico research, we demonstrate that ticks share several similarities with other venomous taxa. Many tick salivary protein families and their previously described functions are homologous to proteins found in scorpion, spider, snake, platypus and bee venoms. This infers that there is a structural and functional convergence between several molecular components in tick saliva and the venoms from other recognized venomous taxa. We also highlight the fact that the immune response against tick saliva and venoms (from recognized venomous taxa) are both dominated by an allergic immunity background. Furthermore, by comparing the major molecular components of human saliva, as an example of a non-venomous animal, with that of ticks we find evidence that ticks resemble more venomous than non-venomous animals. Finally, we introduce our considerations regarding the evolution of venoms in Arachnida.
\end{abstract}

Conclusions: Taking into account the composition of tick saliva, the venomous functions that ticks have while interacting with their hosts, and the distinguishable differences between human (non-venomous) and tick salivary proteins, we consider that ticks should be referred to as venomous ectoparasites.

Keywords: Ticks, Venom, Secreted proteins, Toxicoses, Pathogens, Convergence

\section{Introduction}

As haematophagous (blood sucking) arthropods, ticks are mainly considered as ectoparasites that use their salivary constituents to successfully obtain a blood meal by targeting major physiological pathways involved in host defense mechanisms [1]. Ticks constitute an important pest affecting agricultural development, as well as domestic animal and human health since they transmit a variety of infectious agents. Tick saliva has been described as a complex mixture of pharmacologically active compounds with implications for pathogen transmission [1]. From a functional and evolutionary point of view, Fry and colleagues [2], considered the feeding secretions

\footnotetext{
* Correspondence: valdjj@gmail.com

${ }^{3}$ Institute of Parasitology, Biology Centre of the Academy of Sciences of the Czech Republic, České Budějovice 37005, Czech Republic

Full list of author information is available at the end of the article
}

of some haematophagous invertebrates (such as ticks) as a specialized subtype of venom. Certainly, Ixodida, that includes hard and soft tick species, is proven to be a venomous taxonomic Order in Chelicerata [3]. In fact, the bite from a single tick can produce several types of toxicoses [4]; paralysis being the most common and recognized form of tick-induced toxicoses $[3,5]$.

Tick paralysis is an ascending motor paralysis produced by an impairment of neurotransmission, possibly due to the blockade of ion channels involved in the depolarization of nervous tissue [6]. This form of polyneuropathy is mainly associated with the acquisition of a blood meal by female ticks and will spread to the upper limbs of the host, causing incoordination and, in some cases, ending with respiratory failure and death [4]. Nevertheless, evident signs of toxicoses (e.g., paralysis) are not a sine qua non effect from the tick bite as in the 
case of other venomous taxa, such as snakes, spiders, scorpions or pseudoscorpions. This observational scarcity is perhaps the reason ticks are not considered venomous animals. Thus, tick saliva as venom has rarely been mentioned in parasitological literature, with the exception of a few examples (e.g., as in [7]).

Traditionally, venom was defined as a toxic fluid that inflicts an abrupt death or paralysis in the host and/or prey. This archaic concept, however, partially highlights the deleterious effects of venom on the host/prey and lacks ecological relevance. After investigating many venomous animals, Fry and colleagues $[2,8]$ extended this limited definition of venom "as secretions produced in specialized glands and delivered through a wound (regardless of the wound size), that interferes with normal physiological processes to facilitate feeding or defense by the animal that produces the venom". By interfering with normal host physiological processes infers that all toxins are venomous, but not all venomous proteins are toxic. This new paradigm allows us to consider a wider spectrum of envenomation produced by a myriad of macromolecules. In our study we hypothesize that due to their salivary composition ticks are venomous animals within the phylum Chelicerata. We base our hypothesis on the following points: (i) the various toxic effects induced by ticks (ii) the convergent protein families present in spiders, scorpions and ticks; (iii) the immunomodulatory properties found in ticks saliva is also found in other venomous taxa (iv) the pattern of immune response against toxins by the host/prey is similar in both ticks and other venomous taxa; (v) the structural similarities in members of major protein families between known venomous taxa and ticks; (vi) the bimodal structural dichotomy between human (non-venomous) and tick saliva; and, finally (vii), the phylogenetic position of parasitiformes (Ixodida, Holothyrida and Mesostigmata) as a sister clade of pseudoscorpiones based on [9].

\section{Results and discussion}

\section{Toxicoses phenomena within ixodida}

The Australian Ixodes holocyclus is perhaps the best example of a tick that induces paralysis on livestock [10], pet animals [11], and humans [12]. Tick-induced paralysis, however, is not limited to this tick species but has been reported for $\sim 8 \%$ of all tick species from major tick genera, except Carios and Aponomma [3] (69 out of approximately 869 tick species; 55 hard tick species and 14 soft tick species). Some of these paralyses inducing tick species represented in Figure 1 are also endemic to and abundant in several geographic regions [4]. Examples in the distribution of such ticks species are the North American Ixodes scapularis, Dermacentor variabilis and Amblyomma americanum [13,14], the South American Amblyomma cajannense [15], the European
Ixodes ricinus [16], and the globally distributed Rhipicephalus sanguineus [17].

Additionally, several lethal and paralysis inducing toxins have been identified in ticks. For example, the $15.4 \mathrm{kDa}$ acidic salivary toxin secreted by Ornithodoros savignyi is highly abundant and its purified form kills a mouse within 90 minutes at a concentration of $400 \mu \mathrm{g} / 10 \mathrm{~g}$ of mouse weight [20]. Another purified basic toxin from the same tick species was shown to kill a 20 g mouse within $30 \mathrm{mi}-$ nutes after administration of $34 \mu \mathrm{g}$ of the toxin [21]. Verified via Western blot, a $20 \mathrm{kDa}$ trimeric neurotoxin was identified in the salivary glands of Rhipicephalus evertsi evertsi that paralyzed muscle contractions in an in vitro assay [22,23]. Maritz and colleagues (2001) identified a $60 \mathrm{kDa}$ toxin in Argas walkerae that reduces [3H]glycine release from crude rat brain synaptosomes, indicating a paralytic effect. Other toxins have also been identified in tick egg extract from Amblyomma hebraeum, R. e. evertsi, R. microplus, $R$. decoloratus and Hyalomma truncatum, (revised in [4]). The presence of these toxins in tick eggs may be related to the protection of the egg mass against predation in natural environments - adding a new function for venoms in ticks, i.e., defense.

Besides tick paralysis, other types of toxicoses can be induced by a particular tick species, including sand tampan toxicoses by $O$. savignyi, sweating sickness, Mhlosinga, Magudu, and necrotic stomatitis nephrosis syndrome by $H$. truncatum, spring lamp paralysis in South Africa by $R$. e. evertsi, and, finally, specific toxicoses induced by $R$. microplus, D. marginatus, $R$. appendiculatus, I. rekicorzevi and O. gurneyi (revised in [3]). Toxicoses by R. microplus, $H$. truncatum and $R$. appendiculatus induce an anorexigenic effect [3], as induced by the secreted toxin Bv8 from the skin of the fire-bellied toad, Bombina variegata [24]. Symptoms of general toxicoses were also reported after soft tick bites that include pain, blisters, local irritation, oedema, fever, pruritus, inflammation and systemic disturbances [25]. Recently, human and canine toxicoses induced by the argasid tick O. brasiliensis, known as "mouro" tick, were reported and the most frequent symptoms of toxicoses induced by this tick species were local pruritus, slow healing lesions, local edema and erythema, and local skin rash [26]. Different types of immune reactions can also be included in the general scope of tick toxicoses [3,27]. Immediate and delayed skin hypersensitivity was reported in cattle exposed to $R$. microplus and $R$. decoloratus antigens $[28,29]$, and in dogs exposed to $A$. cajennense antigens [30].

There are important factors in considering the severity of tick-induced toxicoses. (i) As stated by Paracelsus, the dose makes the poison. For example, I. rubicundus induces Karoo paralysis in South African livestock only when critical infestation densities are reached during repletion [31]. (ii) The anatomical location where the tick 

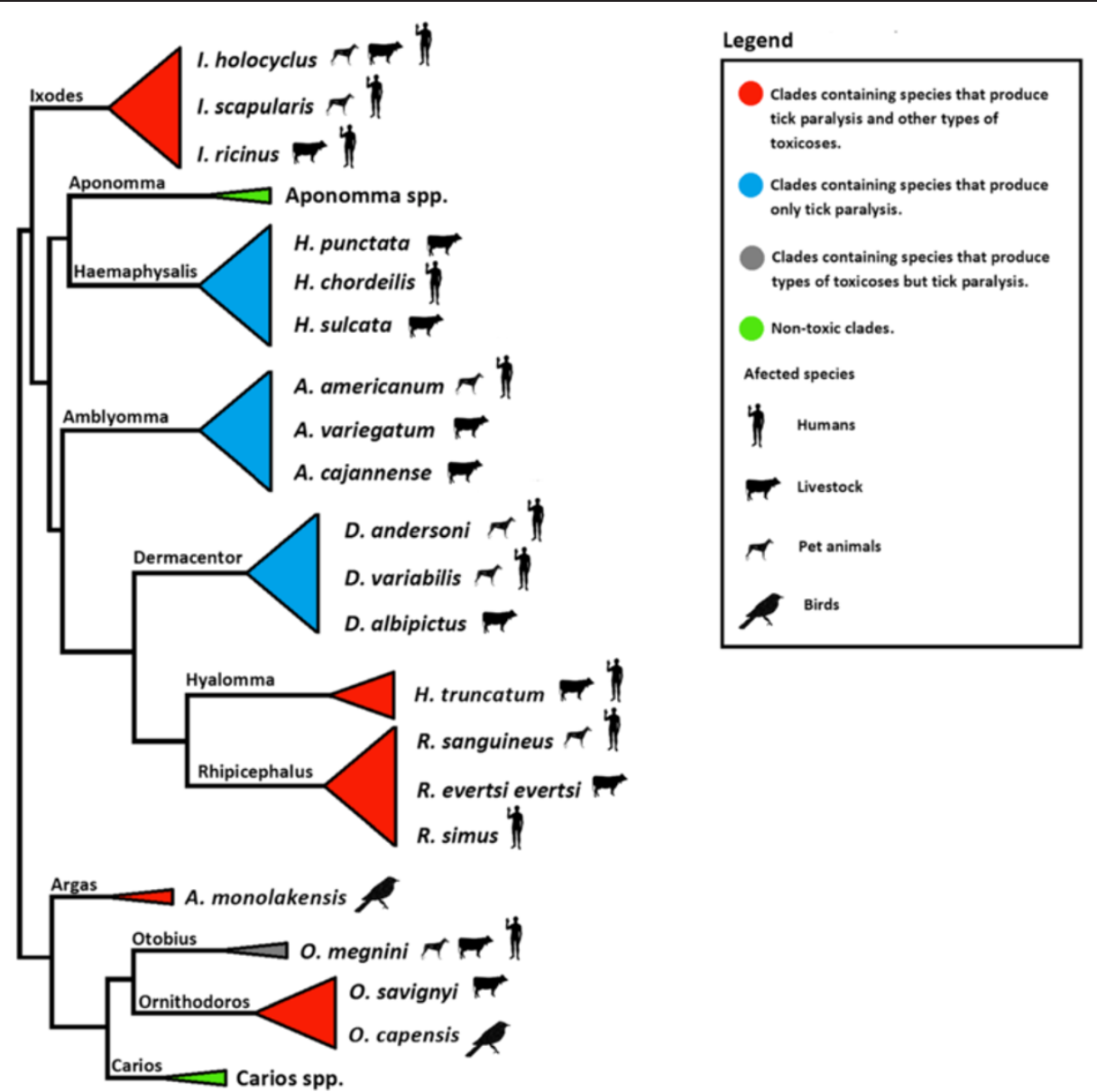

Figure 1 Phylogenetic distribution of the major tick toxicoses-inducing genera. The phylogenetic tree was compiled from published sources $[18,19]$. Data regarding tick toxicoses among Ixodida genera and presented tick species was collected from [3].

saliva is inoculated also seems to play a role in the toxic output. Although the tick species was not identified, a case report described a 3 year-old Indian boy with an acute onset of left-sided facial palsy secondary to tick infestation in the left ear [32]. Therefore, the proximity to a nerve (in this case the facial nerve) was important for the clinical toxic output (left-sided facial palsy). A similar case was also reported in a 3 year-old Turkish girl [33]. (iii) The duration of tick feeding is also an important factor of induced toxicoses [4]. Venzal and colleagues [34] showed that, after 3 days, laboratory mice infested with Ornithodoros aff. puertoricensis had initial signs of hyperaemia, followed by respiratory symptoms on day 4 , and finally after 4 days the mice displayed nervous incoordination. A final factor (iv) to consider is the presence of common antigens between tick saliva and hosts. Recent episodes of human anaphylaxis after allergic sensitizations induced by bites of $A$. americanum have been reported. Patients with a history of A. americanum bites produced increased levels of pro-allergenic immunoglobulin E (IgE). The increased anti-tick IgE levels in these patients were correlated to anaphylactic reactions to one anti-cancer monoclonal antibody (Cetuximab) and red meats [35]. Anaphylaxis induced by $A$. americanum is provoked by the presence of specific IgE to the carbohydrate galactose-alpha-1,3-galactose (alpha-gal) that is also present in Cetuximab and red meat [35]. Interestingly, alpha-gal was recently found in the gut of I. ricinus, a tick that also induces anaphylaxis [36].

The unified view of venom immune modulation and antivenom immune responses

The haematotoxic and neurotoxic effects associated with venom exposure are widely recognized (revised in [2]). Nevertheless, all venomous animals are also constantly challenged by the host/prey or predator immune response. Studies have shown that the immune response of laboratory animals successfully counteracted venomous toxins [37,38]. In fact, natural resistance to snake venom was reported in both prey $[39,40]$ and predator [41]. Thus, the immune system of the host/prey must constitute an important target of venoms in order to be 
effective. In fact, manipulating host defense mechanisms by venoms has been reported for some venomous animals like the parasitoid wasp, Nasonia vitripennis [42]. $N$. vitripennis, like ticks, are considered to be an ectoparasite since the Nasonia larvae feed on their hosts (invertebrates) without entering the host body [42]. The venom of $N$. vitripennis must suppress the immune response of the hosts in such a way that the host "allows" the parasitoid infection while simultaneously, the host will be able to control infections by other microorganism that otherwise would compete with the $N$. vitripennis larvae development [43]. Two major host defense cascades were suppressed by $N$. vitripennis venom: the phenoloxidase cascade and the coagulation cascade [43]. Several components of $N$. vitripennis venom have been suggested to modulate the host immune system, e.g., serine protease inhibitors, serine proteases, cystein-rich/Kunitz venom proteins and cysteine-rich/trypsin inhibitor-like venom proteins [43].

Manipulation of the host/prey immune system is not restricted to venomous Hymenoptera, e.g., N. vitripennis; for example, the haematophagous bat Desmodus rotundus, a venomous animal based on its salivary composition and feeding behavior [44], possesses two members of TNF- $\alpha-$ stimulated gene 6 (TSG-6) family that are highly expressed in its salivary glands. The TSG-6 family members have specific anti-inflammatory properties, such as the inhibition of neutrophil migration to interact with macrophage CD44 and modulation of NF-kB signaling [45]. This suggests that TSG-6 may play a feeding-facilitating role by suppressing the immune system. One well-studied example is the immune modulation induced by ticks in their hosts. The immune system manipulation by ticks is a complex process that has been recently revised [1].

Ticks are unique among hematophagous arthropods since they attach to host skin and feed for several days, while other blood-feeding arthropods (e.g. Triatomes or mosquitoes) feed little and often. Therefore, ticks need to counteract both the immediate innate immunity and the slower-developing adaptive immune responses in their vertebrate hosts. One first line of defense will be to counteract pain and itching responses of the host by targeting, for example, histamine, an immune-related mediator of pain and itch (revised in [1]). A few histamine-binding lipocalins was reported in the hard tick, $R$. appendiculatus [46]. In this regard, tick venom differs from canonical venoms since most venomous animals (e.g., wasps, bees, snakes, scorpions, spiders and jellyfish) will induce pain or an itch response. These venomous animals use their venom systems as a defensive or predatory function [47] with the desired effects of pain or itch to produce a deterrent effect. In contrast, similar to ticks, venomous haematophagous animals, like $D$. rotundus or triatomes bugs, should counteract prey/host awareness in order to feed until repletion.
After the skin is injured by a tick bite, the inflammatory response of the host will be activated. Ticks require a molecular arsenal to suppress both the cellular and molecular components of the host defenses. Tick salivary extract have been shown to reduce endothelial cell expression of the adhesion molecules ICAM-I and VCAM-I (Dermacentor andersoni) and P-selectin (I. scapularis). Reduction in adhesion molecules will reduce the extravasation of leukocytes at the site of tick attachment. The alternative pathway of complement activation is also one of the targets of the immunomodulation induced by tick saliva and thus complement inhibition activity has been reported in saliva of D. andersoni, I. scapularis, I. ricinus, I. hexagonus, I. uriae and O. moubata (revised in [1]). In addition, as a general trend, the saliva from haematophagous arthropods, including ticks, inhibit the proliferation of naive $\mathrm{T}$ cell and the production of Th1 citokines [48]. One interesting example of modulating the adaptative immune response by hard ticks is Japanin. Japanin is a lipocalin that specifically reprograms human dendritic cells by hijacking the normal maturation process, even in the presence of "danger" signals like bacterial lipopolysaccharide [49]. Interestingly, Japanin promotes secretion of the anti-inflammatory cytokine IL-10 and increases expression of programmed deathligand 1 (PD-L1), and both are involved in suppressing $\mathrm{T}$ cell immunity and induction of tolerogenic responses [49]. Such degree of molecular specialization has neither been described in other haematophagous arthropods nor in other venomous taxa. However, despite the immune suppression induced by tick saliva, some tick-host interactions result in immune-mediated acquired resistance to ticks after subsequent tick challenge.

Given the dynamics between induction of immune suppression by venoms and host/prey resistance development, an arms race between the host immune system and venomous components has been proposed [40]. The balance of this arms race will result in a susceptible or resistant host, prey or predators. In our revision of the topic, we found a convergence in the type of immune response that mammals display against both venom and tick saliva. Type 2 immune responses are mediated by lymphocytes T helper type 2 (Th2), IgE and IgG1 antibodies, but also by eosinophils, mast cells, basophils and, alternatively, by activated macrophages. This Th2 immune response encompasses a wider concept, namely allergies [50]. In mammals, venoms can induce allergic sensitization and development of specific IgE [37,38,51]; tick feeding also induces a Th2 polarization [1], specific IgE $[52,53]$, and causes allergic sensitization [35]. The complex association between allergen IgE recognition with histamine secretion by mast cells and basophils that subsequently provoke uncomfortable reactions in animals has been highlighted [50]. This association goes beyond a specific neutralizing IgE antibodies response to a 
more complex detection of sensory stimuli by the olfactory, gustatory and visual systems that, surprisingly, may eventually result in developing aversive behaviors to specific locations or foods [50]. This suggests that the evolution of a differentiated pattern of immunity against venoms, including tick saliva, may have yet unexplored ecological implications. Another example of immune response convergence against venoms is that mast cells can be activated by the venom of scorpions without the concomitant presence of specific IgE [54], suggesting that the protective activities of mast cells is independent to the high affinity binding of IgE to the IgE receptor (FcERI) present on mast cells. Wada and colleagues [55] recently showed that the protective role of mast cells in resistant mice to the tick Haemaphysalis longicornis was also independent of FceRI. The above referenced studies show that (i) immune modulation may be a major function of venoms and (ii) the type of immune response elicited against the venom of ticks and other venomous taxa undergo similar immune pathways, thus tick saliva may possess venom-like molecules.

\section{Tick saliva; or, the structural convergence of venomous proteins with venomous functions}

The types of toxicoses induced by tick bites (ranging from lethal paralysis to local hypersensitivity) is not limited to the presence of lethal toxins but also to the presence of specific tick salivary protein families common among other venomous taxa. Recent advances in sequencing technologies have revealed an amazing body of information from the salivary glands of both hard and soft ticks [56-64]. From these high-throughput investigations, several protein families have been identified that are involved in tick-host interactions. Such protein families are found in the venoms of several other Metazoan species [2]. Examples of such venomous protein families found in tick saliva are defensins [65], lectins [66], cystatins [67], lipocalins [21,68-71], hyaluronidase [72], phospholipase A2 [73], Kunitz-like peptides [56,74,75], metalloproteases [76], AVIT [77], CAP proteins (CysteineRich Secretion Proteins, Antigen 5, and Pathogenesis-Related) [2] and sphingomyelinase D [2].

Not only are these protein families present in tick saliva, but they also possess major functions described in conventional venomous systems. These functions include inhibition of thrombin, fXa, fVII/tissue factor system, platelet aggregation (i.e., collagen-induced, ADP-induced), act as a GPIIb/IIIa receptor antagonist, or affect fibrino (geno)lytic activity (revised in [2]). At the molecular level, venomous agents display common characteristics, despite their numerous biochemical activities and sequence variability, such as (i) possessing a signal peptide, (ii) displaying functional versatility within a protein family, (iii) targeting short-term physiological processes and, (iv) stabilizing their tertiary structures via disulfide bonds. Finally, after being recruited as a functionally stable venomous agent, (v) duplication events occur to reinforce its adaptation (for a thorough description of said characteristics see [2]). An exception to this last property (gene duplication) is seen in platypus venom [78]. In the following sections we show the structural convergence between tick Kunitz peptides, cystatins, defensins, lipocalins, lectins and phospholipase $\mathrm{A}_{2}$ and their conventional venomous counterparts.

\section{Kunitz peptides}

Kunitz peptides were named after Moses Kunitz who first discovered it in 1936 from bovine pancreas [79]. Since then, expression of the Kunitz protein family has been found in basically all kingdoms of life. Recent reports show that Kunitz peptides have undergone a massive gene expansion by gene duplication in the salivary glands of both I. scapularis [56] and I. ricinus [80], possibly due to specific selective pressures during the evolution of the tick-host interaction [81]. The Kunitz structure has been described with diverse functions in several venomous animals, including spiders and scorpions. Some Kunitz peptides from venomous animals possess dual activities by inhibiting both proteases and ion channels; examples of such toxins are LmKKT-1a from the scorpion Lychas mucronatus [82] and HuwentoxinXI (HWTX-XI) from the spider Ornithoctonus huwena [83]. These venomous toxins have diversified their amino acid sequence causing a positive net charge on the allatom Kunitz landscape (see Figure 2A). Reports have shown that toxins possessing a positive surface are most likely to target ion channels [84].

To date, only a few salivary secreted tick Kunitz peptides have been structurally resolved; however, these few reports reveal the venomous nature of these salivary peptides compared with other Kunitz structures from venomous animals. Figure 2A shows that the archetypal Kunitz fold is highly conserved for these tick salivary peptides and that they are structurally similar to HWTX-XI and LmKKT-1a. These structurally resolved tick salivary peptides show a structural conservation in their disulfide bridges (indicated by roman numerals), $\beta$-hairpin and the $\mathrm{C}$-terminus $\alpha$ helix. The only deviant from the archetypical Kunitz tertiary structure is Ra-KLP, since it is missing the second (II) disulfide bridge and possess a modified apex due to two atypical disulfide bridges ( 1 and 2; Figure 2A). Figure 2A also shows that the electrostatic potential of HWTX-XI and LmKKT-1a is strikingly similar to both TdPI and RaKLP, both from the salivary glands of $R$. appendiculatus. Ra-KLP has been reported as an ion channel modulator [85] like LmKKT-1a and HWTX-XI with no protease activity. It remains to be tested, however, if and how TdPI affects ion channels. Figure 2B shows a C $\alpha$ backbone 


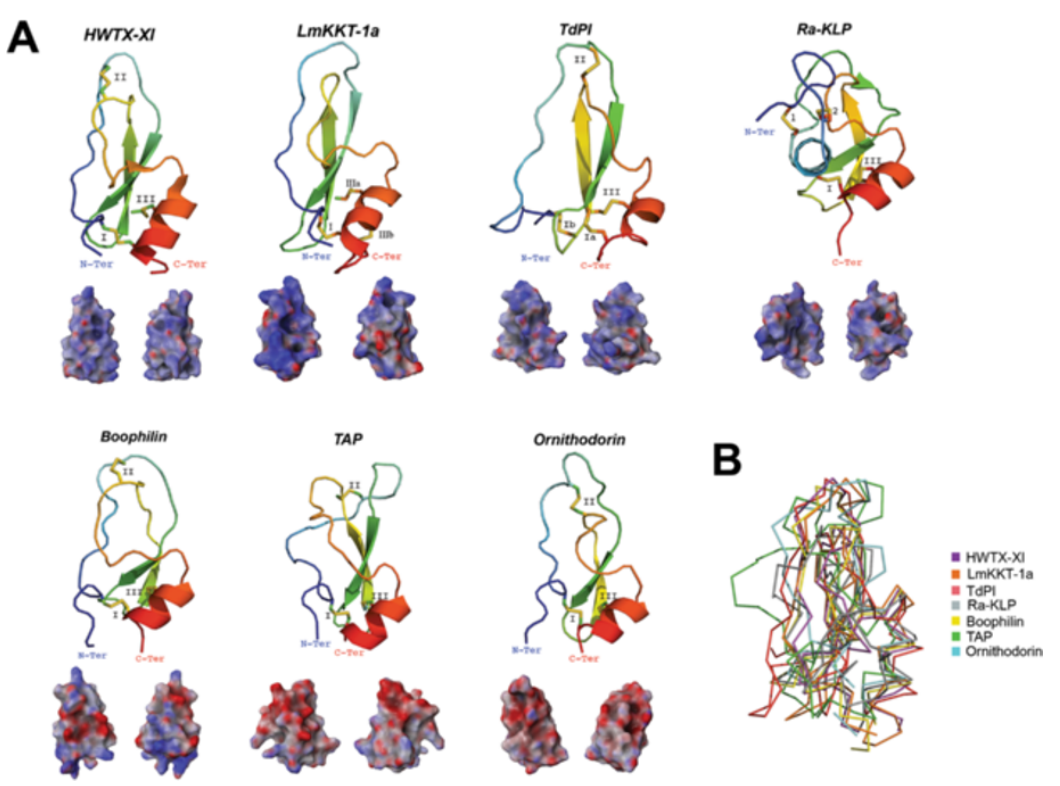

Figure 2 Tertiary structures of tick salivary Kunitz peptides. Panel A displays tertiary structure of toxins from spider (HWTX-XI; PDB: 2JOT) and scorpion (LmKKT-1a; PDB: 2 M01), and five tick salivary Kunitz-like peptides (PDBs: TAP-1D0D; ornithodorin-1TOC; boophilin-2ODY; TdPI-2UUX; Ra-KLP-2W8X). The tertiary structures depict the conserved disulfide bridges (indicated by roman numerals), loops, $\beta$-sheets that forms the $\beta$-hairpin, and a-helices. All structures are colored from the $\mathrm{N}$-terminus (blue) to the C-terminus (red). Below each tertiary structure is the respective electrostatic potential in $180^{\circ}$ turns (blue = positive; red = negative; white $=$ neutral). A tertiary structural alignment in Panel $\mathbf{B}$ depicts the Ca protein backbone (color codes for each structure is presented on the right). (Note: For Panel A we used the C-terminus domain for both ornithodorin and boophilin since these possess two Kunitz-domains).

protein structural alignment of the represented Kunitz peptides. The root mean square deviation compared with HWTX-XI does not exceed $3 \AA$ (TAP $=3 \AA$; ornithodorin = 2.4 $\AA$; boophilin $=1.7 \AA$; TdPI $=2.8 \AA$; Ra-KLP $=2.8 \AA$ ); the structural difference with LmKKT-1a slightly varies from these deviations, but does not exceed 3.3 A. Regardless of the conservative nature in the Kunitz fold, these tick salivary peptides display functional versatility and target different short-term physiological processes [85-89]. Therefore, as one of the most abundant tick salivary protein families [80], we consider Kunitz peptides as a typical example of a venomous agent that fit all five properties (i-v) referred above and described by Fry and colleagues [2].

\section{Cystatins}

Although cystatins have been identified from the venomous glands of spiders [90], snakes [91] and caterpillars [92], the venomous function of these cystatins remain elusive. Protease inhibition is the most common activity reported for these cystatins, as in one of the earliest studied cystatins isolated from the venom glands of the African puff adder (Bitis arietans) that inhibits papain, cathepsin B and dipeptidyl peptidase I [93]. The inhibitory sites of cystatins that bind during protein-protein interactions are the $\mathrm{N}$-terminal loop and the two $\beta$-hairpin loop regions (indicated in Figure 3A as 1-3). A total of 95 cystine knot toxins have been identified in the venom glands of the tarantula Chilobrachys jingzhao and several of these toxins were reported to inhibit ion channels [90]. Two disulfide bonds form cystine knot toxins with their backbone connected by a third disulfide bond and the overall structure is invariably stabilized by $\beta$-sheets. Examples of these cystine knot toxins are Kunitz and defensin peptides. Although its toxic effects remain elusive, the cystatin JZTX-75 was among the 95 cystine knot toxins identified in the venom glands of the tarantula $C$. jingzhao [90]. The predicted tertiary structure of JZTX-75 (shown in Figure 3A) possesses a slightly positive electrostatic potential.

Over 80 cystatins have been reported in the salivary glands of hard and soft tick species [57,61,63,64,77,94]. For a full description on the physiological role of tick cystatins refer to [67]. In general, tick cystatins are potent inhibitors of papain-like cysteine proteases and play important roles during tick feeding. Tick salivary cystatins have been shown to serve as host immune modulators but their basic functions in tick saliva are unknown. A secreted cystatin has also been identified in the tick gut of $H$. longicornis that increases in expression during feeding on its host (Hlcyst-2; Figure 3A) [95]. Three crystal structures of cystatins secreted by tick salivary glands of I. scapularis (sialostatinL and sialostatinL2) and O. moubata (OmC2) have been resolved. Although 


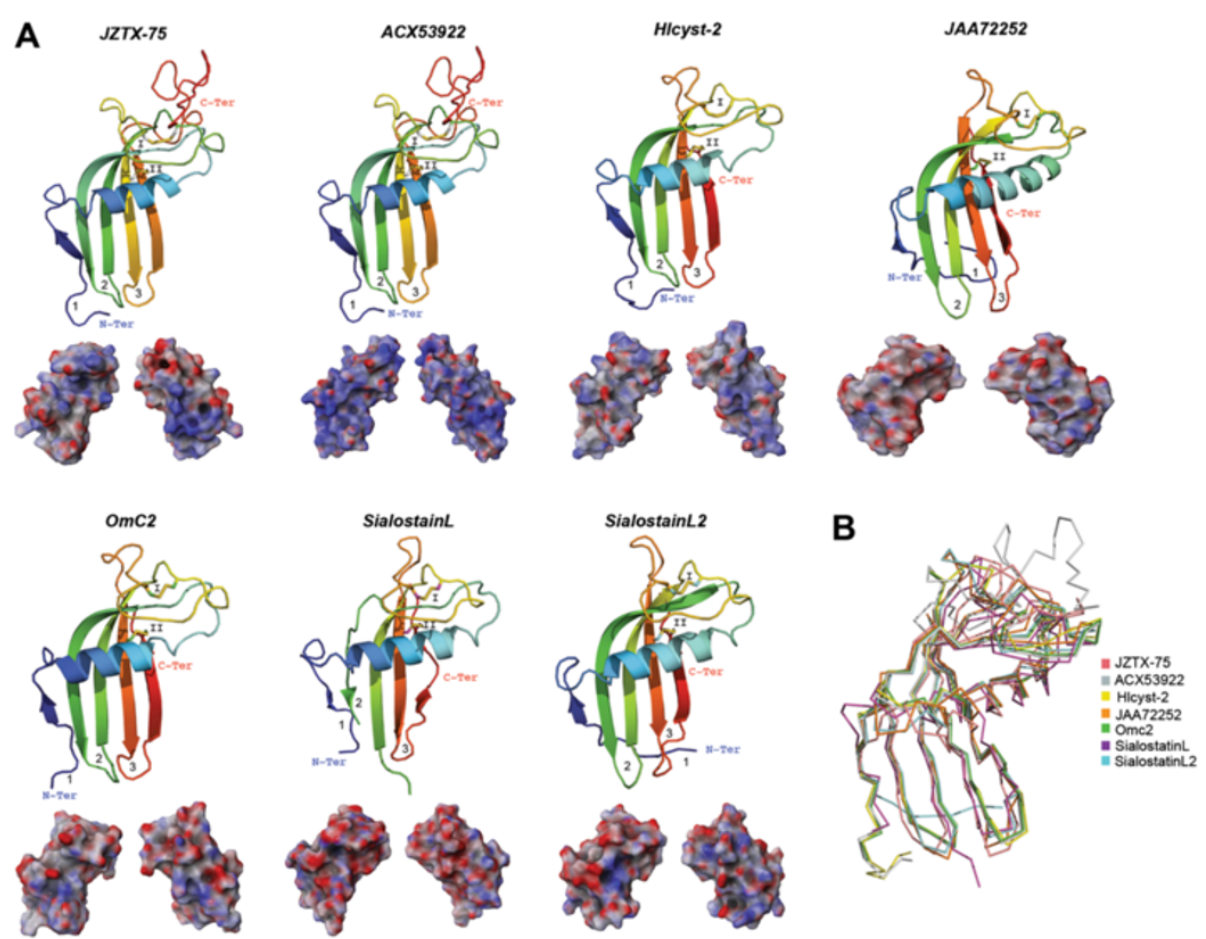

Figure 3 Tertiary structures of tick salivary cystatins. Panel A displays predicted tertiary structure of a cystatin from spider venom (JZTX75; GenBank: ABY71743) and, from tick salivary glands, we present three predicted cystatin structures (GenBank: ACX53922, JAA72252 and Hlcyst2-ABV71390) and three crystal structures (PDBs: OmC2-3LOR; sialostatinL-3LI7; sialostatinL2-3LH4). The tertiary structures depict the conserved disulfide bridges (indicated by roman numerals), $\beta$-sheets, the a-helix, and the inhibitory loop regions (1-3). All structures are colored from the $\mathrm{N}$-terminus (blue) to the C-terminus (red). Below each tertiary structure is the respective electrostatic potential in $180^{\circ}$ turns (blue $=$ positive; red $=$ negative; white $=$ neutral). A tertiary structural alignment in Panel $\mathbf{B}$ depicts the Ca protein backbone (color codes for each structure is presented on the right). (Note: For Panel $\mathbf{A}$ we used the $\mathrm{C}$-terminus domain for sialostatinL).

the binding of these tick cystatins remain elusive, an in silico study showed that these inhibitory loop regions for sialostatinL2 are conserved (Figure 3) [67]. A recent study showed that several tick cystatins were constantly expressed during a 5-day feeding period; among these was the cystatin ACX53922 [96]. Compared with the other five cystatins in Figure 3A, ACX53922 displays a more positive electrostatic potential throughout its allatom landscape while still maintaining the archetypal tertiary backbone structure (Figure 3B; all structures have $<3.0 \AA$ root mean square deviation compared with JZTX-75).

\section{Defensins}

As in the Kunitz family, defensin peptides are widely distributed among the kingdoms of life as they are found in plants [97], jellyfish, sponges, nematodes, crustaceans, arachnids, insects, bivalves, snails, sea urchins, birds [98] and mammals [99], including humans [100]. The two structural classes of defensins are, (i) those exclusive to vertebrate known as $\alpha$ - $\beta$ - and $\theta$-defensins [101] and (ii), the most extended, possessing a simple structural motif known as the cysteine-stabilized $\alpha$-helix and $\beta$-sheet
$(\mathrm{CS} \alpha \beta)[102]$ as those depicted in Figure 4A. Defensins have a wide range of biological functions, varying from sweet-tasting proteins to antimicrobial peptides (AMP) [102]. Recruitment of defensins has been reported in scorpion [103,104], snake [105], lizard [106], platypus [107] and spider [108] venom glands. The main function of defensins as animal toxins is to target ion channels [102]. Defensin molecules can also possess multiple biological functions that include ion channel modulation, antimicrobial and antifungal activity, such as crotamine, the $\beta$-defensin myotoxin from the rattlesnake Crotalus durissus terrificus [109]. In contrast, although isolated from the spider venom of Ornithoctonus hainana, the Oh-defensin was shown so far to only possess antimicrobial activity [108].

A single experimentally induced genetic deletion or mutation transforms a non-toxic defensin into a neurotoxin [99], thus, reinforcing the concept that toxic molecules are recruited from ancestral proteins possessing a non-toxic physiological function [2]. This also suggests the evolutionary steps necessary for recruiting defensins in the venom of venomous animals [99]. In agreement with the functional diversity of defensins, it is evident, 

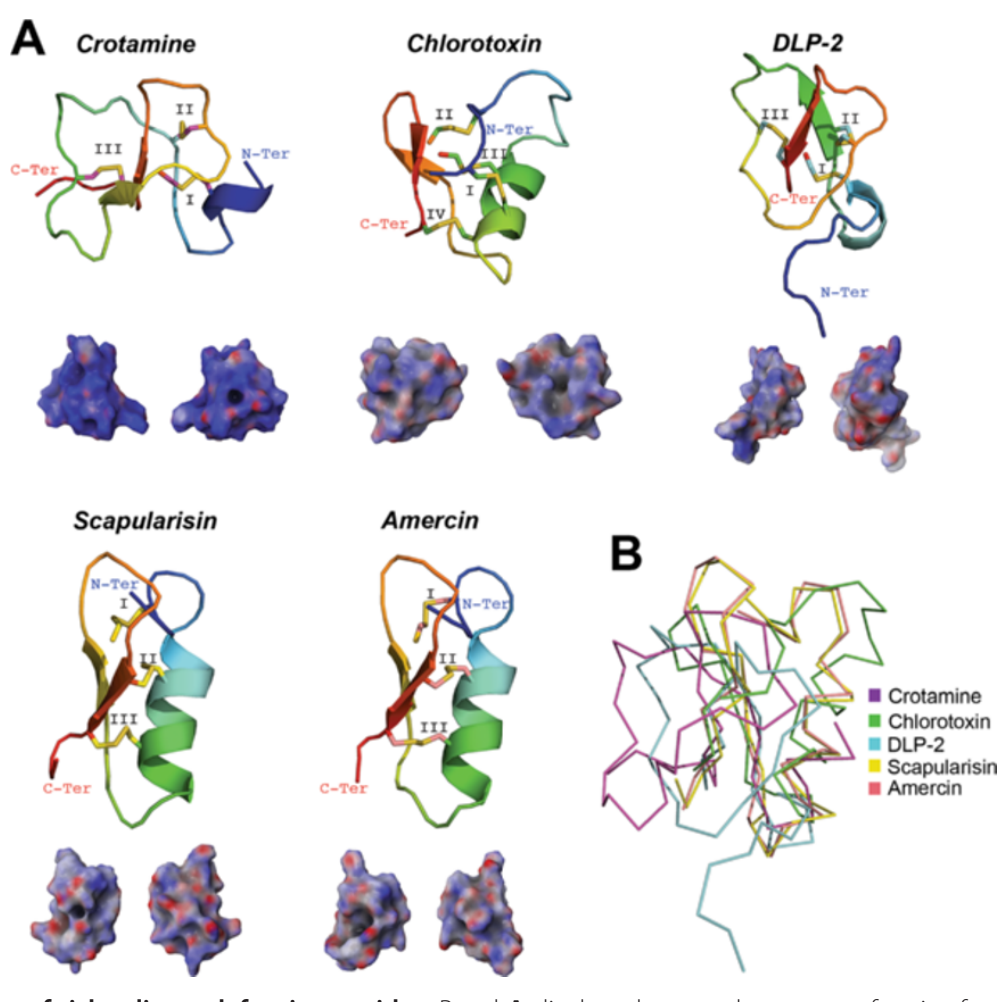

Figure 4 Tertiary structures of tick salivary defensin peptides. Panel A displays the crystal structure of toxins from rattlesnake (crotamine; PDB: 1299), scorpion (chlorotoxin; PDB: 1CHL) and platypus (DLP-2; PDB: 1D6B), and two predicted tertiary structures from tick salivary glands (GenBank: scapularisin-AAV74387 and amercin-ABI74752). The tertiary structures depict the conserved disulfide bridges (indicated by roman numerals), loops, $\beta$-sheets that forms the $\beta$-hairpin, and the a-helix. All structures are colored from the $\mathrm{N}$-terminus (blue) to the $\mathrm{C}$-terminus (red). Below each tertiary structure is the respective electrostatic potential in $180^{\circ}$ turns (blue = positive; red = negative; white $=$ neutral). A tertiary structural alignment in Panel $\mathbf{B}$ depicts the Ca protein backbone (color codes for each structure is presented on the right).

from reported crystal structures, that the tertiary structure is highly divergent (Figure $4 \mathrm{~B}$; all have $\sim 3.5 \AA$ root mean square deviation compared with crotamine). Defensins in ticks show a diverse expression pattern, thus they have been isolated from tick haemocytes, gut, intestine, ovaries, malpighian tubules and fat body $[110,111]$. Nevertheless, some of these defensins are exclusively expressed in tick salivary glands [112]. The most widely reported defensin structure in both hard and soft tick species is the CS $\alpha \beta$ [113]. The only function assigned to the majority of characterized tick defensins, thus far, is AMP [65,110-112]; however, haemolytic activity was also recently reported for I. ricinus and $H$. longicornis defensins $[111,114]$. This obviously does not exclude the possibility that tick defensins may have other toxic functions in the vertebrate host. Other types of cysteine-rich AMPs from ticks were found to inhibit serine proteases [115], specifically chymotrypsin and elastase [116]. Furthermore, some tick defensins have secondary and tertiary structures similar to membrane potential modulators, such as scorpion neurotoxins, snake safaratoxins and plant $\gamma$-thionins [117] suggesting a toxic role for these tick defensins. Another example of evolutionary convergence between ticks defensins and toxic defensins are the recently discovered multigenic defensin-like peptides, scasin and scapularisin, from the toxicoses-inducing tick I. scapularis (scapularisin is shown in Figure 4A) [65]. Of these functionally uncharacterized novel defensin-like peptides, scasins show a strong positive selection acting on the whole molecule [65], an evolutionary pattern observed before in conotoxins from the molluscs of the genera Conus [118] that act as ion channel modulators [119]. Nevertheless, further studies should clarify whether scapularisin and scasins are ion channel effectors, or not. As Figure 4A shows, however, tick defensins have similar electrostatic potentials as those found in snake and scorpion venom.

\section{Lipocalins}

Lipocalins are multifunctional proteins with a $\beta$-barrel structure that share three conserved domains in their primary structure, namely, motifs $1-3$. Lipocalins have been implicated in development, regeneration, and pathological processes, but their specific roles are not known [120]. In reptiles and other venomous taxa, venom systems are enriched through gene duplication 
[2,121], thereby increasing its functional divergence to develop a new function or neofunctionalization [47]. Neofunctionalization in tick lipocalins is a good example of functional diversification found in the venom of several venomous taxa [2].

Lipocalin-scaffolds have frequently been recruited as tick salivary components. Examples of toxin recruitment in tick salivary glands are the sand tampan toxins (TSGP) from O. savignyi, an abundant protein group that form a phylogenetic cluster with members of the tick lipocalin protein family, suggesting that they originated via gene duplication [21,69-71]. Three TSGPs were isolated from salivary gland extract in the tampan $O$. savignyi: the toxins TSGP2 that produces ventricular tachycardia, TSGP4 that produces Mobitz-type ventricular block, and the non-toxic TSGP3 that inhibits platelet aggregation [21,69,71]. Two other lipocalins closely related to TSGP2/TSGP3 are moubatin (platelet aggregation inhibitor; [122]) and OmCI from the soft tick $O$. moubata (complement inhibitor of C5 activation) [123]. It is worth mentioning that OmCI [124], TSGP2 and moubatin have dual action and triple action was reported for TSGP3 [71]. These tick salivary lipocalins are depicted in Figure 5. Multifunctionalization is a common trait found in the toxins of Lonomia obliqua [125] and, as previously mentioned, for defensin peptides found in some venomous systems.

Due to a recent European upsurge of allergic reactions caused by the pigeon tick A. reflexus (e.g. [126]) a major allergen was identified (Arg r1) that is homologous to toxic lipocalins from O. savignyi $[127,128]$. Histaminebinding proteins were also described as lipocalins from the tick saliva of $R$. appendiculatus [46] and recently, a novel group of lipocalins was reported from metastriate tick saliva possessing a modulatory activity on dendritic cells [49]. Another lipocalin was isolated from A. monolakensis (AM-33) that binds to cysteinyl leokotrienes with high affinity, avoiding endothelial permeability and formation of edema, thus ensuring the tick to replete an erythrocyte-rich meal [129].

\section{Phospholipase A2}

The phospholipase $\mathrm{A}_{2}\left(\mathrm{PLA}_{2}\right)$ superfamily are ubiquitously found throughout the animal kingdom to catalyze the hydrolysis of ester bonds in a variety of different phospholipids producing lysophospholipids and free
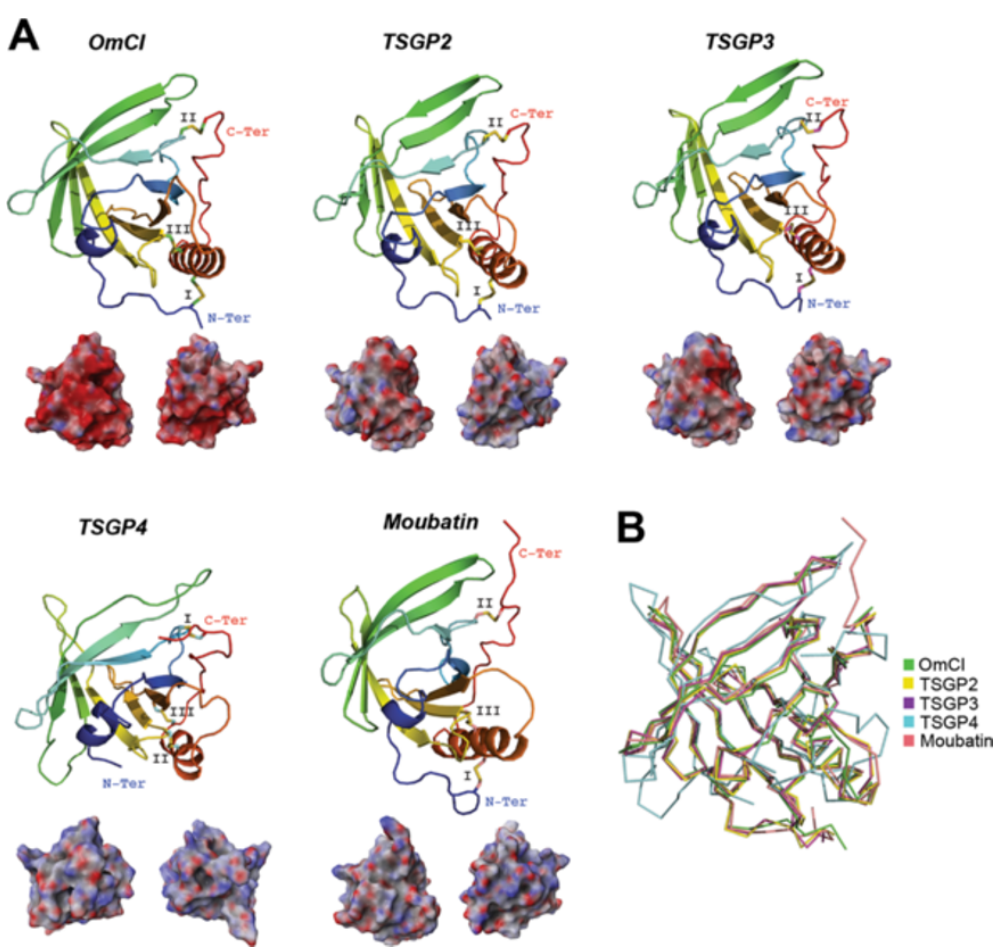

Figure 5 Tertiary structures of tick salivary lipocalins. Panel A displays the crystal structure of the tick lipocalin OmCl from $O$. moubata (; PDB: 3ZUO) and four predicted tertiary structures from the tick toxins, namely TSGP2, TSGP3, TSGP4 from O. savignyi and moubatin, also from $O$. moubata (respective UniProt: Q819U1, Q819U0, Q819T9 and Q04669). The tertiary structures depict the conserved disulfide bridges (indicated by roman numerals), loops, $\beta$-sheets that forms the $\beta$-hairpin, and the a-helix. All structures are colored from the $\mathrm{N}$-terminus (blue) to the $\mathrm{C}$-terminus (red). Below each tertiary structure is the respective electrostatic potential in $180^{\circ}$ turns (blue $=$ positive; red $=$ negative; white $=$ neutral). A tertiary structural alignment in Panel $\mathbf{B}$ depicts the Ca protein backbone (color codes for each structure is presented on the right). All structures have $<2.2 \AA$ root mean square deviation compared with OmCl. 
fatty acids that play important physiological roles [130]. The $\mathrm{PLA}_{2}$ superfamily includes five distinct enzyme types that are composed of 15 groups with many subgroups depending if they are secreted, cytosolic, calciumindependent or based on their specific target [131]. The $\mathrm{PLA}_{2}$ superfamily has also been recruited via convergent evolution into the toxic arsenal of cephalopods, cnidarians, insects and arachnids [2]. In the venom of reptiles, $\mathrm{PLA}_{2}$ appears as an antiplatelet aggregation factor [132], a myotoxin and a neurotoxin [133].

As previously stated, tick toxicoses is related to feeding and feeding cycle. Tick salivary gland $\mathrm{PLA}_{2}$ activity was found to be higher in engorged $A$. americanum compared with unfed ticks and this increase was correlated with salivary gland secretion [134]. Although the function remains unknown, the $\mathrm{PLA}_{2}$ activity found in the saliva of $A$. americanum was suggested to play an important role during prolonged tick feeding (10-14 days for $A$. americanum) [73]. The salivary $\mathrm{PLA}_{2}$ from $A$. americanum is alkaline ( $\mathrm{pH}: 9.5)$, as previously reported for $\mathrm{PLA}_{2}$ from bee and snake venom [73], and does not contribute to the anticoagulant activities found in the saliva of $A$. americanum [135], but possess hemolytic activity [73]. The $\mathrm{PLA}_{2}$ from both tick [136] and rattlesnake [137] possess antibacterial activities, suggesting a functional confluence between these two venomous species. Nevertheless, the $\mathrm{PLA}_{2}$ from $A$. americanum was not inhibited by aristolochic acid [73] as previously reported for the $\mathrm{PLA}_{2}$ from the venomous snake, Vipera ammodytes meridionalis [138]. Sousa and colleagues [139] demonstrated the complexity of the toxic effects induced by venomous molecules since the $\mathrm{PLA}_{2}$-melitin complex in Apis mellifera venom acted as a vasoconstrictor on rat aorta; however, no effect was evidenced for the $\mathrm{PLA}_{2}$ and melitin fractions individually. New methods for testing the molecular functions of tick molecules may contribute to unravel the intricate putative toxic effects of tick salivary $\mathrm{PLA}_{2}$. For example, a new method for dsRNA delivery was reported using I. scapularis eggs and nymphs, incorporating electroporation instead of microinjection. One of the genes that were successfully silenced was a putative $\mathrm{PLA}_{2}$ from I. scapularis [58]. We compared this putative PLA $\mathrm{PA}_{2}$ from $I$. scapularis (GenBank: EW812932), and a few other putative $\mathrm{PLA}_{2}$ from ticks that induce toxicoses (most are depicted in Figure 1) with the crystal structure of the $\mathrm{PLA}_{2}$ present in A. mellifera venom (PDB: 1POC; Figure 6A) and a predicted model from the scorpion toxin, imperatoxin-I that targets the sarcoplasmic reticulum calcium-release channel of skeletal and cardiac muscles [140]. Although these tick $\mathrm{PLA}_{2}$ have $<1.8 \AA$ root mean square deviation compared with $A$. mellifera (Figure $6 \mathrm{~B}$ ), they have lost the disulfide bridge IV that is present in A. mellifera $\mathrm{PLA}_{2}$ (Figure 6A). A recent study reports that, due evolutive

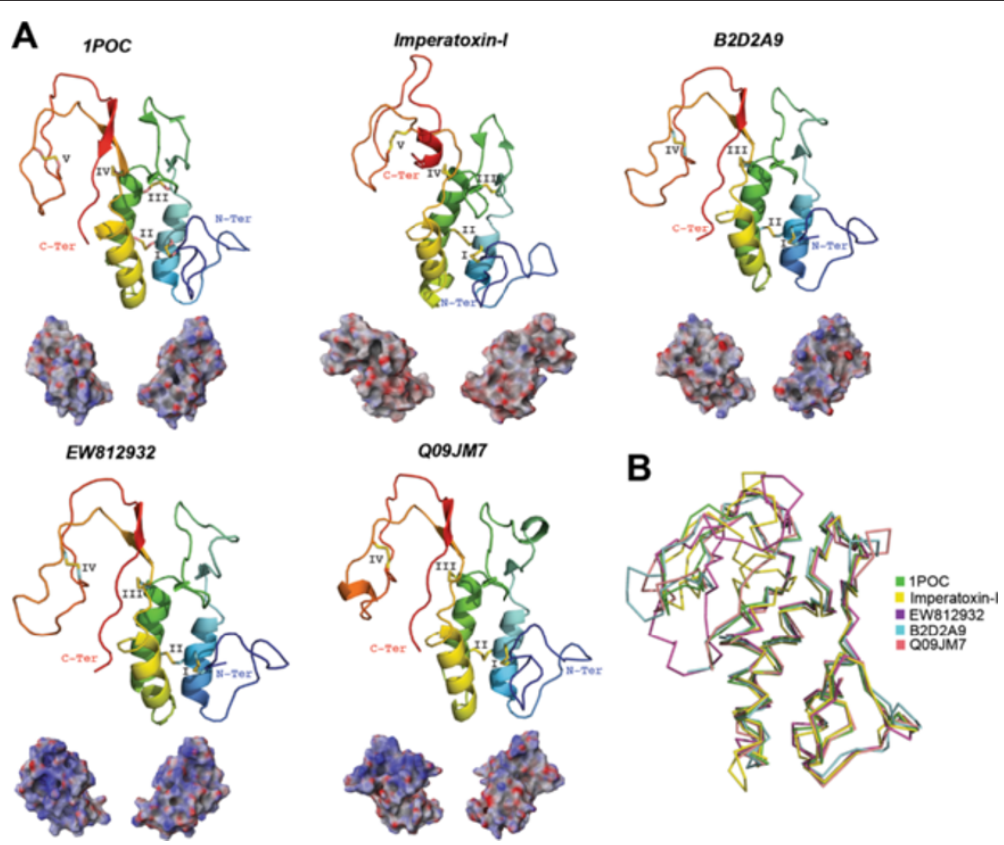

Figure 6 Tertiary structures of tick salivary PLA $\mathbf{A}_{2}$. Panel $\mathbf{A}$ displays the crystal structure of the PLA $A_{2}$ from bee venom of $A$. mellifera (PDB: 1POC) and four predicted tertiary structures, three tick PLA (respective UniProt: B2D2A9, Q09JM7 and the translated sequences GenBank: EW812932) and the scorpion toxin, imperatoxin-I (UniProt: P59888). The tertiary structures depict the conserved disulfide bridges (indicated by roman numerals), loops, and the a-helix. All structures are colored from the N-terminus (blue) to the C-terminus (red). Below each tertiary structure is the respective electrostatic potential in $180^{\circ}$ turns (blue = positive; red = negative; white = neutral). A tertiary structural alignment in Panel $\mathbf{B}$ depicts the Ca protein backbone (color codes for each structure is presented on the right). 
pressures caused during the arms race with the host(s), ticks express non-canonical variants of highly conserved protein families and these variants possess an altered disulfide bridge pattern that provide functional flexibility e.g., Kunitz protein family from I. ricinus [80].

\section{Lectins}

Lectins can be defined as a wide variety of carbohydratebinding proteins and glycoproteins from viruses, bacteria, fungi, protista, plants, and animals [141]. Lectins found in snake venom mainly affect blood coagulation pathways [142] and can also act as anti-angiogenic compounds [143]. In caterpillars, lectins are known to function as anticoagulants as in the Lonomia venom [92], but may also possess a myotoxic effect as in stonefish venom [144]. To date, tick lectin research has mainly focused on its roles in tick innate immunity (for revision see $[145,146])$. Earlier studies, however, showed that $R$. microplus saliva possesses lectin activity and induces immunosuppression in mice [147]. Additionally, Rego and colleagues $[66,148]$ reported four tick lectins, two from $O$. moubata (Dorin M and OMFREP) and two from $I$. ricinus (Ixoderin A and Ixoderin B). Based on phylogenetic analysis and expression pattern, a putative role in tick innate immunity was assigned to Ixoderin $\mathrm{A}$ and OMFREP. The role of Ixoderin B still remains unknown since it was exclusively expressed in the salivary glands and presented sequence divergence compared with Ixoderin $\mathrm{A}$ and OMFREP. Figure 7A depicts these tick lectins compared with ryncolin1 from the venom of the dog-faced water snake, Cerberus rynchops (all structures have $<1.8 \AA$ root mean square deviation; Figure 7B), which was suggested to induce platelet aggregation and/or initiate complement activation [149]. We note that IxoderinB also (as in Kunitz and PLA $\mathrm{P}_{2}$ ) does not possess the archetypal disulfide bridge pattern (II; Figure 7A). In addition to its sequence divergence to Ixoderin $\mathrm{A}$ and OMFREP, the missing disulfide bridge of IxoderinB may cause a more flexible fold thus diversifying its target(s).

\section{A comparison of salivary proteins from humans and ticks} In order to compare the saliva of ticks to the saliva of a non-venomous animal we established a comparison
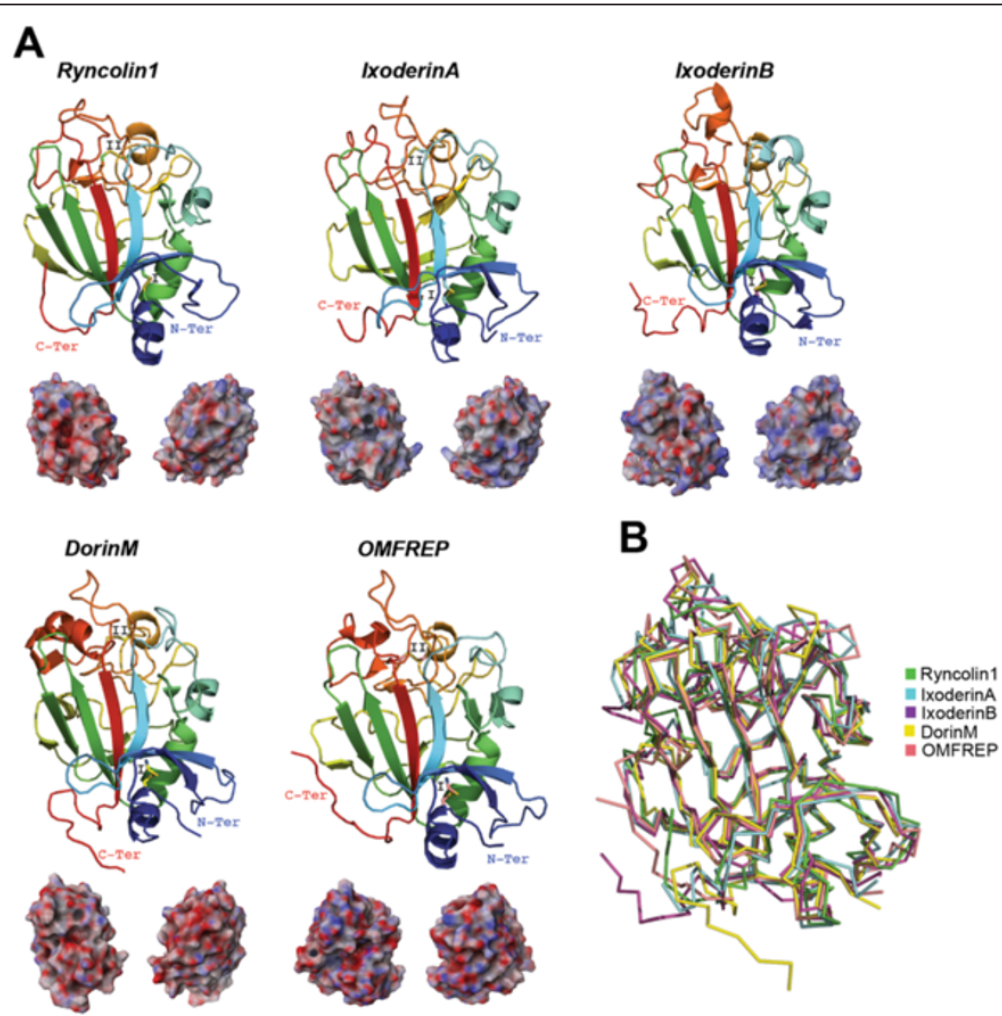

Figure 7 Tertiary structures of tick salivary lectins. Panel A displays five predicted tertiary structures ryncolin1 from snake venom (UniProt: D8VNS7) and four tick lectins, IxoderinA, IxoderinB, DorinM, OMFREP (respective UniProt: 16LAP5, Q5IUW6, Q7YXM0 and Q8MUC2). The tertiary structures depict the conserved disulfide bridges (indicated by roman numerals), loops, $\beta$-sheets that forms the $\beta$-hairpin, and the a-helix. All structures are colored from the $\mathrm{N}$-terminus (blue) to the C-terminus (red). Below each tertiary structure is the respective electrostatic potential in $180^{\circ}$ turns (blue = positive; red = negative; white = neutral). A tertiary structural alignment in Panel $\mathbf{B}$ depicts the Ca protein backbone (color codes for each structure is presented on the right). 
between human and tick salivary systems. Recent proteomic studies have identified a total of 2698 proteins in human saliva (revised in [150]). The major protein components of human saliva are amylase, carbonic anhydrase, mucins, cystatins, proline-rich proteins, histatins, statherins and antibodies (revised in [150]), but it also contains defensins, lactoperoxidases, lysozymes and lactoferrins [151]. The complexity of the saliva from nonvenomous animals (e.g., humans) is akin to that of ticks, but there are major differences in the molecular functions, the structure and the electrostatic potential of common salivary protein families. The two salivary systems present similar components such as lysozymes, cystatins, lipocalins, defensins and PLA2s. There are also differences, for example, human saliva possesses histatins and statherins, but these proteins have not been found in tick saliva. Despite that human salivary glands and the Kunitz protein family have been scientifically investigated for some time, the authors are unaware of any reports indicating the presence of Kunitz peptides (i.e., the archetypal 60 aa long peptide) in human saliva. The main reports for human Kunitz (also found in saliva) are of domains from larger proteins, e.g., immunoglobulins. Additionally, although the lectin intelectin-1 (UniProt: Q8WWA0) has been found in human saliva, its specific tertiary structure may drastically differ from those currently reported since a PSI-BLAST against the PDB was unable to retrieve a homologous structure and thus we were unable to model this human salivary lectin. In addition, human saliva does not present any allergen-like molecules; as are found in tick saliva. These differences are not surprising if we consider the different alimentary regimes these two species have and the molecular functions these two salivary systems need to perform. The phylogenetic distance between human and ticks maybe the most rational explanation for such differences. The salivary composition of the venomous mammal $D$. rotundus, however, is similar to ticks. $D$. rotundus salivary glands possess both Kunitz proteins and allergen-like molecules, while also possessing humans salivary components, like statherins and lysozymes [44]. As discussed above, this suggests that venomous animals recruit in their salivary glands a special set of proteins with specific venomous functions.

For the protein families we report here, the available tertiary structures for humans (and those we were able to model) are cystatins, defensins, lipocalins and PLA2 (Figure 8). There seems to be a bimodal diversity among these salivary protein families. Figure 8 shows that cystatins and lipocalins are structurally conserved, however, the electrostatic potential differs considerably - as dramatically displayed in OmCI. The opposite is seen for defensins and PLA2s - similar electrostatic potential surface with dissimilar tertiary structures. This bimodal diversity is also evidenced within these protein families from venomous organisms compared to their human counterparts. The defensin crotamine, for instance (Figure 4), is structurally similar to human $\beta$-defensin1 (Figure 8), but their electrostatic potential and landscape differs (crotamine being more basic). It is worth mentioning that the tick salivary proteins depicted in Figure 8 are from some of the toxicoses-inducing ticks represented in Figure 1.

\section{Considerations on the most recent common ancestor of Parasitiformes and Pseudoscorpiones}

Given the evidence provided in the previous sections, we find it necessary to reconsider ticks as venomous ectoparasites due its salivary properties and its evolutionary implications. Arthropods represent a major component of the biodiversity of life on Earth and venom systems, as an evolutionary adaptation, appear many times in Arthropoda (e.g., spiders, scorpions, wasp, bees and flies). With a few exceptions in Hexapoda (i.e., bees and some wasps), the main function of venomous molecular systems amongst Arthropods is to assist in predation [47]. Ticks are haematophagous Arachnids and, based on morphological characteristics, it has been argued that Holothyrida is the sister taxa of Ixodida [18]. This evolutionary relationship with Holotryrida, free-living mites that mainly feed on the body fluids of dead arthropods [152], has lead to inferences regarding the feeding habits of the most recent common ancestor (MRCA) of ticks, which has been described as a saprophytic organism [153] or a scavenger in which haematophagy evolved subsequently [81]. Entomophagy was another type of predatory behavior proposed for the MRCA of ticks and the cannibalism observed in some soft tick species was an argument in favor of this hypothesis [81].

Haematophagy has evolved several times from predation in Insecta; for example, triatomine and cimicid bugs evolved from predatory heteropterans and Symphoromyia (and other hemathophagous flies) evolved from predatory ones [154]. The characteristics of the MRCA of ticks are paramount in understanding the evolution of tick salivary constituents. Recently, by using maximum likelihood, Bayesian and parsimony analyses of over 41 kilobases of DNA sequence from 62 single-copy nuclear protein-coding genes, Regier and colleagues [9] presented a strong, revised and actualized phylogeny of Arthropoda. In these phylogenetic analyses, Parasitiformes (Acari) appears as a sister group of Pseudoscorpions (Figure 9A). The phylogenetic position of Pseudoscorpions in Chelicerata has caused large debate in recent years. By using 2907 amino acids from 13 different proteins, another series of phylogenetic analyses by Ovchinnikov and Masta [155] also showed that Pseudoscorpions, although not a sister group, are closely related to Parasitiformes. From both studies $[9,155]$, we could certainly infer that 


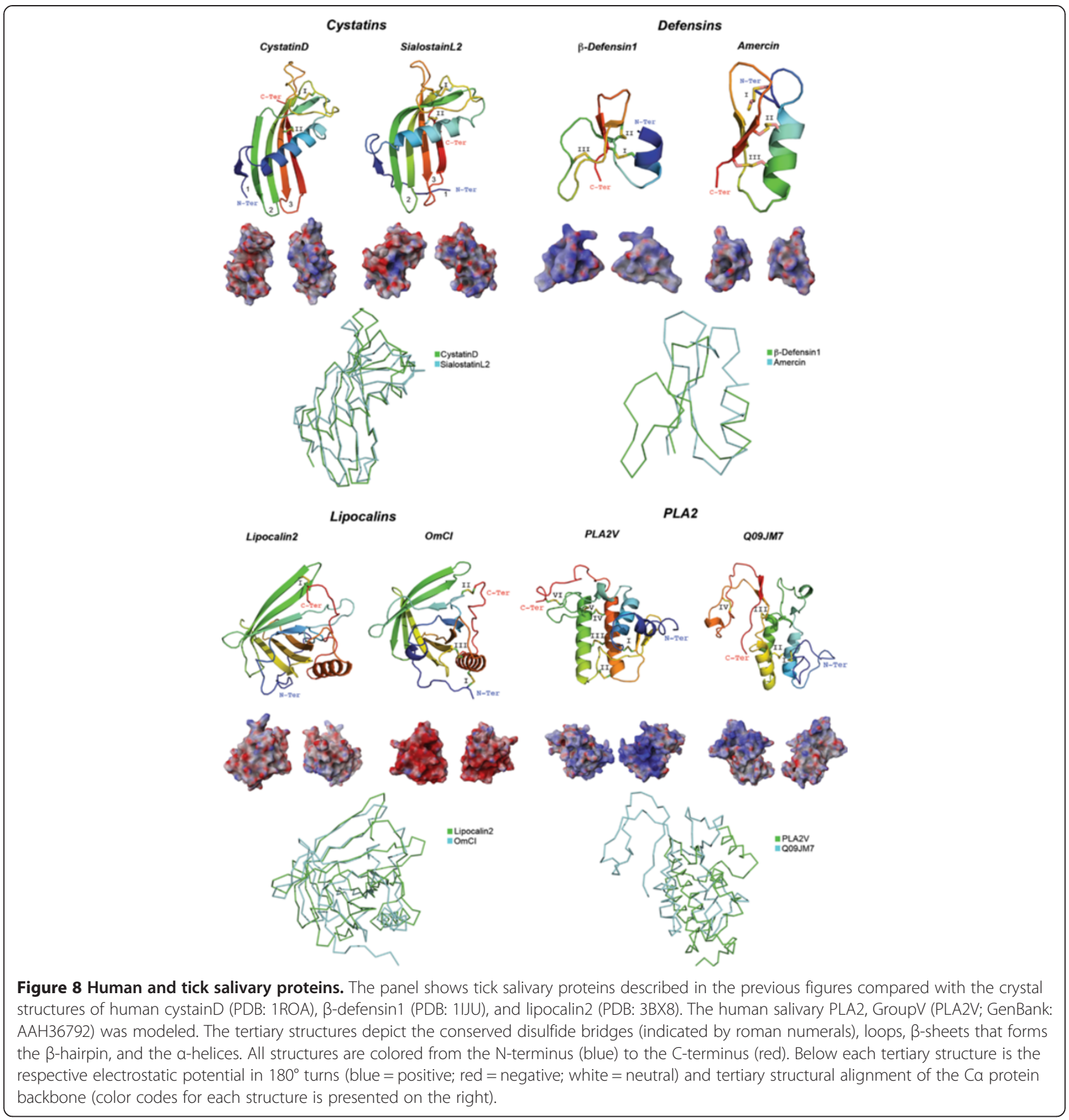

Pseudoscorpions and ticks share a recent common ancestor.

Pseudoscorpions are venomous members of Chelicerata [156] that, together with spiders and scorpions [2], constitute well-known examples of venomous animals amongst Chelicerata. Our working hypothesis is that the MRCA of ticks was a venomous predator of smaller preys that later evolved to feed on larger vertebrates. In agreement with this, the feeding plasticity (as a capacity of feeding on several hosts) of the tick ancestor was recently suggested [157]. The convergence of several protein families between tick saliva and the venom of spiders and scorpions is shown in Figure 9A. This suggests a common origin in the venom systems of these three taxa (pseudoscorpions were not included in the comparison due to a lack of information regarding the venom composition of this species). Additionally, ticks are questing animals that will move actively in order to find their hosts [158-160]. Questing behavior constitute an important trait of tick ecology [158]. The evolution of 

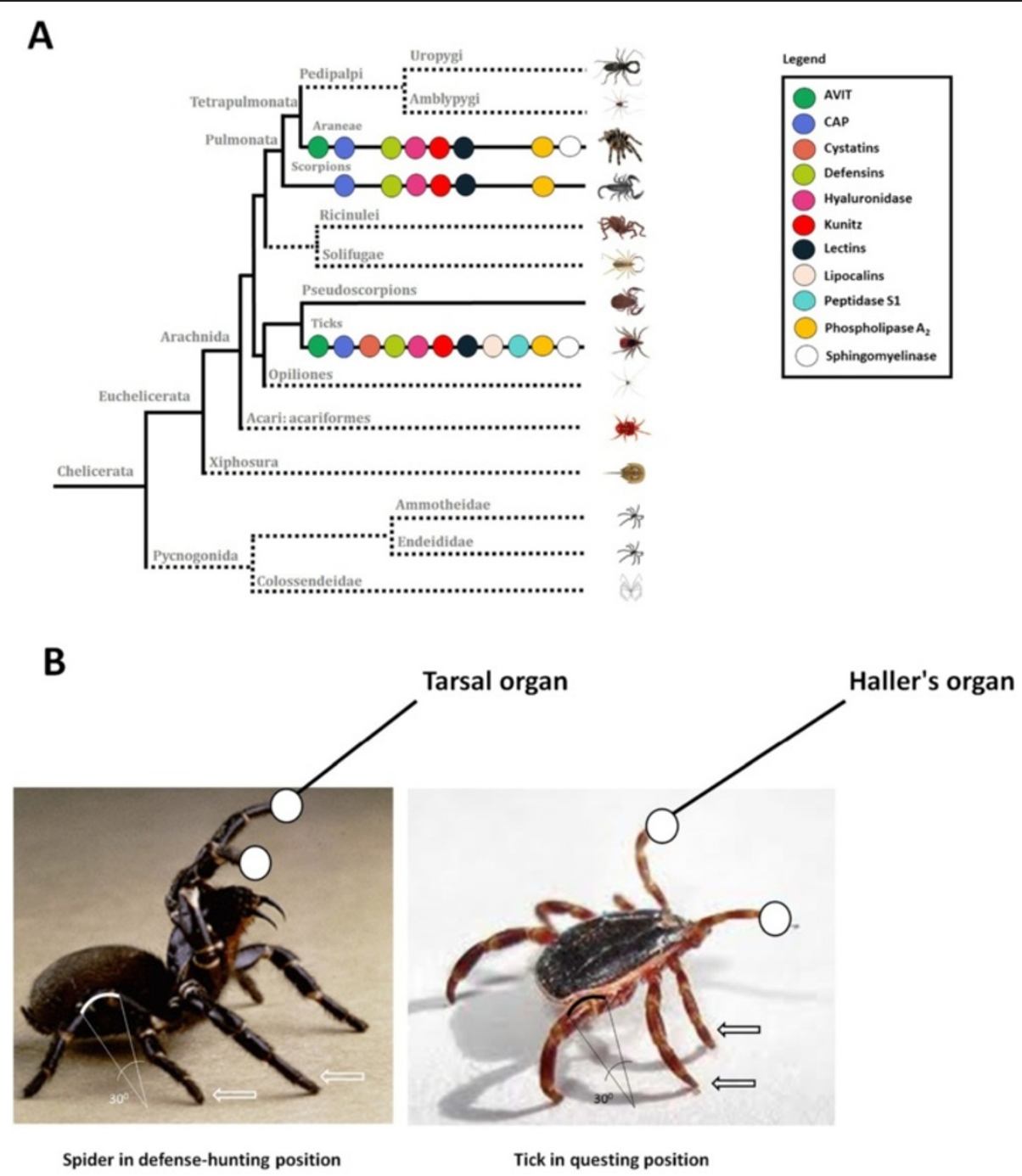

Figure 9 Similarities among venomous animals in chelicerata. Panel A shows the phylogenetic tree compiled from published sources [9]. Data regarding protein families in ticks, spiders and scorpions was collected from [2], as well as protein families characterized in recent studies. Panel B shows a spider's defense/hunting and a tick's questing positions (photos are not in real dimensional scale). The images depict similarities in attitude, angle of flexion in posterior legs $\left(30^{\circ}\right)$, middle legs (arrows), and first pair of legs exposing the respective sensory organs (white circles).

questing behavior is closely related to the evolution of sensory organs like the Haller's organ [161]. We found striking similarities in the questing behavior and position of sensory organs of ticks compared to the hunting behavior and position of sensory organs [162] of venomous spiders (Figure 9B).

\section{Conclusion}

The literature has split the saliva of haematophagous animals into those who consider the saliva as venomous and those that consider it as a special kind of saliva or a complex cocktail of bioactive components. Just last year (2013) the Journal of Proteomics published two investigations on the salivary gland components of the haematophagous bat Desmodus rotundus, where one refers to it as venomous [44] and the other simply as salivary components [45]. In tick research, the literature predominantly considers tick saliva as a complex cocktail of bioactive components and the toxicoses induced by ticks are mainly discussed in the context of paralysis. These claims narrow the ecological implications of the venomous relationship between ticks and their hosts. To classify ticks as mere ectoparasites is limited and underestimates the venomous structure of multigenic protein families in tick saliva. Therefore, we propose to consider ticks as venomous ectoparasites based on the intrinsic properties of tick saliva. 


\section{Methods}

\section{Tertiary protein modeling, structural alignment and electrostatic potential}

Predicted tertiary models were generated using the Phyre2 server [163]. All predicted models were then refined via minimization and hydrogen-bond network was optimized by means of side chain sampling using the Schrodinger's Maestro Protein Preparation Wizard [164]. The structural deviations (root mean square deviation) were calculated using the protein structural alignment tool, from the Maestro software. Electrostatic potentials were calculated using the Poisson-Boltzmann equation also implemented in the Maestro software.

\section{Abbreviations}

AMP: Antimicrobial peptides; CSaß: Cysteine-stabilized a-helix and $\beta$-sheet; Ig: Immunoglobulin; MRCA: Most recent common ancestor;

PLA 2 : Phospholipase $A_{2}$; PDB: Protein databank; Th2: T helper type 2.

\section{Competing interests}

Both authors declare that they have no competing interests.

\section{Authors' contributions}

Both authors have contributed equally. Both authors read and approved the final manuscript.

\section{Acknowledgements}

JJV was sponsored by project CZ.1.07/2.3.00/30.0032, co-financed by the European Social Fund and the state budget of the Czech Republic. ACC was supported by a grant from the Ministère de l'Education Supérieure et de la Recherche of France.

\section{Author details}

${ }^{1}$ Center for Infection and Immunity of Lille (CIIL), INSERM U1019 - CNRS UMR 8204, Université Lille Nord de France, Institut Pasteur de Lille, Lille, France. ${ }^{2}$ SaBio. Instituto de Investigación de Recursos Cinegéticos, IREC-CSIC-UCLM-JCCM, Ciudad Real 13005, Spain. ${ }^{3}$ Institute of Parasitology, Biology Centre of the Academy of Sciences of the Czech Republic, České Budějovice 37005, Czech Republic.

Received: 7 May 2014 Accepted: 20 June 2014 Published: 1 July 2014

\section{References}

1. Wikel S: Ticks and tick-borne pathogens at the cutaneous interface: host defenses, tick countermeasures, and a suitable environment for pathogen establishment. Front Microbiol 2013, 4:337.

2. Fry BG, Roelants $K$, Champagne DE, Scheib H, Tyndall JDA, King GF, Nevalainen TJ, Norman JA, Lewis RJ, Norton RS, Renjifo C, de la Vega RC R: The toxicogenomic multiverse: convergent recruitment of proteins into animal venoms. Annu Rev Genomics Hum Genet 2009, 10:483-511.

3. Mans BJ, Gothe R, Neitz AW: Biochemical perspectives on paralysis and other forms of toxicoses caused by ticks. Parasitology 2004, 129:S95-S111.

4. Estrada-Peña A, Mans BJ: Tick-induced paralysis and toxicoses. In Biology of ticks, Volume Volume 2. 2nd edition. Edited by Sonenshine DE, Roe RM. USA: Oxford University Press; 2013:313-332.

5. Edlow JA, McGillicuddy DC: Tick paralysis. Infect Dis Clin North Am 2008, 22:397-413

6. Maritz C, Louw Al, Gothe R, Neitz AW: Neuropathogenic properties of Argas (Persicargas) walkerae larval homogenates. Comp Biochem Physiol A Mol Integr Physiol 2001, 128:233-239.

7. Motoyashiki T, Tu AT, Azimov DA, Ibragim K: Isolation of anticoagulant from the venom of tick, Boophilus calcaratus, from Uzbekistan. Thromb Res 2003, 110:235-241.

8. Fry BG, Roelants J, Norman JA: Tentacles of venom: toxic protein convergence in the kingdom Animalia. J Mol Evol 2009, 68:311-321.
9. Regier JC, Shultz JW, Zwick A, Hussey A, Ball B, Wetzer R, Martin JW, Cunningham CW: Arthropod relationships revealed by phylogenomic analysis of nuclear protein-coding sequences. Nature 2010, 463:1079-1083.

10. Bagnall BG, Doube BM: The Australian paralysis tick Ixodes holocyclus. Aust Vet J 1975, 51:159-160.

11. Illkiw JE, Turner DM, Howlett CR: Infestation in the dog by the paralysis tick Ixodes holocyclus. I. Clinical and histological findings. Aust Vet J 1987, 64:137-139.

12. Pearn J: The clinical features of tick bite. Med J Aust 1977, 2:313-318.

13. Barbour AG, Fish D: The biological and social phenomenon of Lyme disease. Science 1993, 260:1610-1616.

14. Rydzewski J, Mateus-Pinilla N, Warner RE, Nelson JA, Velat TC: Ixodes scapularis (Acari: Ixodidae) distribution surveys in the Chicago metropolitan region. J Med Entomol 2012, 49:955-959.

15. Beati L, Nava S, Burkman EJ, Barros-Battesti DM, Labruna MB, Guglielmone AA, Cáceres AG, Guzmán-Cornejo CM, León R, Durden LA, Faccini JL: Amblyomma cajennense (Fabricius, 1787) (Acari: Ixodidae), the Cayenne tick: phylogeography and evidence for allopatric speciation. BMC Evol Biol 2013, 13:267.

16. Stanek G: Pandora's Box: pathogens in Ixodes ricinus ticks in Central Europe. Wien Klin Wochenschr 2009, 121:673-683.

17. Gray J, Dantas-Torres F, Estrada-Peña A, Levin M: Systematics and ecology of the brown dog tick, Rhipicephalus sanguineus. Ticks Tick Borne Dis 2013, 4:171-180.

18. Klompen JSH, Black WC, Keirans JE, Norris DE: Systematic and biogeography of hard ticks, a total evidence approach. Cladistics 2000, 16:79-102.

19. Murrel A, Campbell NJH, Barker SC: A total-evidence phylogeny of ticks provides insights into the evolution of life cycles and biogeography. Mol Phylogenet Evol 2001, 21:244-258.

20. Neitz AWH, Howell CJ, Potgieter DJJ: Purification of the toxic component in the oral secretion of the sand tampan Ornithodoros savignyi Audouin (1827). J South Afr Chem Ind 1969, 22:142-149.

21. Mans BJ, Steinmann CM, Venter JD, Louw Al, Neitz AWH: Pathogenic mechanisms of sand tampan toxicoses induced by the tick, Ornithodoros savignyi. Toxicon 2002, 40:1007-1016.

22. Viljoen GJ, Bezuidenhout JD, Oberem PT, Vermeulen NM, Visser L, Gothe R, Neitz AW: Isolation of a neurotoxin from the salivary glands of female Rhipicephalus evertsi evertsi. J Parasitol 1986, 72:865-874.

23. Crause JC, van Wyngaardt S, Gothe R, Neitz AW: A shared epitope found in the major paralysis inducing tick species of Africa. Exp Appl Acarol 1994, 18:51-59.

24. Negri L, Lattanzi R: Bv8/PK2 and prokineticin receptors: a druggable pronociceptive system. Curr Opin Pharmacol 2012, 12:62-66.

25. Hoogstraal H: Argasid and Nuttalliellid ticks as parasites and vectors. Adv Parasitol 1985, 24:135-238.

26. Reck J, Marks FS, Guimarães JA, Termignoni C, Martins JR: Epidemiology of Ornithodoros brasiliensis (mouro tick) in the southern Brazilian highlands and the description of human and animal retrospective cases of tick parasitism. Ticks Tick Borne Dis 2013, 4:101-109.

27. Wikel SK: Tick and mite toxicoses and allergy. In Handbook of Natural Toxins, Volume 2. Edited by Tu AT. New York: Marcel Dekker; 1984:371-396

28. Marufu MC, Chimonyo M, Mans BJ, Dzama K: Cutaneous hypersensitivity responses to Rhipicephalus tick larval antigens in pre-sensitized cattle. Ticks Tick Borne Dis 2013, 4:311-316.

29. Marufu MC, Dzama K, Chimonyo M: Cellular responses to Rhipicephalus microplus infestations in pre-sensitised cattle with differing phenotypes of infestation. Exp Appl Acarol 2014, 62:241-522.

30. Mukai LS, Netto AC, Szabo MP, Bechara GH: Hypersensitivity induced in dogs by nymphal extract of Amblyomma cajennense ticks (Acari: Ixodidae). Ann N Y Acad Sci 2002, 969:184-186.

31. Fourie $\sqcup$, Kok DJ: Seasonal dynamics of the Karoo paralysis tick (Ixodes rubicundus): a comparative study on Merino and Dorper sheep. Onderstepoort J Vet Res 1996, 63:273-276.

32. Patil MM, Walikar BN, Kalyanshettar SS, Patil SV: Tick induced facial palsy. Indian Pediatr 2012, 49:57-58

33. Gürbüz MK, Erdoğan M, Doğan N, Birdane L, Cingi C, Cingi E: Case report: isolated facial paralysis with a tick. Turkiye Parazitol Derg 2010, 34:61-64 
34. Venzal JM, Estrada-Peña A, Fernández de Luco D: Effects produced by the feeding of larvae of Ornithodoros aff. puertoricensis (Acari: Argasidae) on laboratory mice. Exp Appl Acarol 2007, 42:217-223.

35. Berg EA, Platts-Mills TA, Commins SP: Drug allergens and food-the cetuximab and galactose-a-1,3-galactose story. Ann Allergy Asthma Immunol 2014, 112:97-101.

36. Hamsten $C$, Starkhammar M, Tran TA, Johansson M, Bengtsson U, Ahlén G, Sällberg $M$, Grönlund $H$, van Hage M: Identification of galactose- $a-1,3$-galactose in the gastrointestinal tract of the tick Ixodes ricinus; possible relationship with red meat allergy. Allergy 2013, 68:549-552.

37. Palm N, Rosenstein R, Yu S, Schenten D, Florsheim E, Medzhitov R: Bee venom phospholipase $A 2$ induces a primary type 2 response that is dependent on the receptor ST2 and confers protective immunity. Immunity 2013, 39:976-985.

38. Marichal T, Starkl P, Reber LL, Kalesnikoff J, Oettgen HC, Tsai M, Metz M, Galli SJ: $A$ beneficial role for immunoglobulin $E$ in host defense against honeybee venom. Immunity 2013, 39:963-975.

39. Heatwole H, Poran NS: Resistances of sympatric and allopatric eels to sea snake venoms. Copeia 1995, 1:136-147.

40. Biardi JE, Coss RG: Rock squirrel (Spermophilus variegatus) blood sera affects proteolytic and hemolytic activities of rattlesnake venoms. Toxicon 2011, 57:323-331.

41. Jansa SA, Voss RS: Adaptive evolution of the venom targeted vWF protein in opossums that eat pitvipers. PLoS One 2011, 6:e20997.

42. Qian C, Liu Y, Fang Q, Min-Li Y, Liu SS, Ye GY, Li YM: Venom of the ectoparasitoid, Nasonia vitripennis, influences gene expression in Musca domestica hemocytes. Arch Insect Biochem Physiol 2013 83:211-231.

43. Danneels EL, Rivers DB, de Graaf DC: Venom proteins of the parasitoid wasp Nasonia vitripennis: recent discovery of an untapped pharmacopee. Toxins (Basel) 2010, 4:494-516

44. Low DH, Sunagar K, Undheim EA, Ali SA, Alagon AC, Ruder T, Jackson TN, Pineda Gonzalez S, King GF, Jones A, Antunes A, Fry BG: Dracula's children: molecular evolution of vampire bat venom. J Proteomics 2013, 89:95-111.

45. Francischetti IM, Assumpção TC, Ma D, Li Y, Vicente EC, Uieda W, Ribeiro JM: The "Vampirome": transcriptome and proteome analysis of the principal and accessory submaxillary glands of the vampire bat Desmodus rotundus, a vector of human rabies. J Proteomics 2013, 82:288-319.

46. Paesen GC, Adams PL, Nuttall PA, Stuart DL: Tick histamine-binding proteins: lipocalins with a second binding cavity. Biochim Biophys Acta 2000, 1482:92-101.

47. Casewell NR, Wüster W, Vonk FJ, Harrison RA, Fry BG: Complex cocktails: the evolutionary novelty of venoms. Trends Ecol Evol 2013, 28:219-229.

48. Fontaine A, Diouf I, Bakkali N, Missé D, Pagès F, Fusai T, Rogier C, Almeras L: Implication of haematophagous arthropod salivary proteins in host-vector interactions. Parasit Vectors 2011, 4:187.

49. Preston SG, Majtán J, Kouremenou C, Rysnik O, Burger LF, Cabezas Cruz A Chiong Guzman M, Nunn MA, Paesen GC, Nuttall PA, Austyn JM: Novel immunomodulators from hard ticks selectively reprogramme human dendritic cell responses. PLOS Pathog 2013, 9:e1003450.

50. Palm NW, Rosenstein RK, Medzhitov R: Allergic host defences. Nature 2012, 484:465-472.

51. Komegae EN, Grund LZ, Lopes-Ferreira M, Lima C: The longevity of Th2 humoral response induced by proteases natterins requires the participation of long-lasting innate-like B cells and plasma cells in spleen. PLoS One 2013, 8:e67135.

52. Kashino SS, Resende J, Sacco AM, Rocha C, Proença L, Carvalho WA, Firmino AA, Queiroz R, Benavides M, Gershwin LJ, De Miranda Santos IK: Boophilus microplus: the pattern of bovine immunoglobulin isotype responses to high and low tick infestations. Exp Parasitol 2005, 110:12-21.

53. Christe M, Rutti B, Brossard M: Susceptibility of BALB/C mice to nymphs and larvae of Ixodes ricinus after modulation of IgE production with anti-interleukin-4 or anti-interferon-gamma monoclonal antibodies. Parasitol Res 1998, 84:388-393.

54. Akahoshi M, Song CH, Piliponsky AM, Metz M, Guzzetta A, Abrink M, Schlenner SM, Feyerabend TB, Rodewald HR, Pejler G, Tsai M, Galli SJ: Mast cell chymase reduces the toxicity of Gila monster venom, scorpion venom, and vasoactive intestinal polypeptide in mice. J Clin Invest 2011, 121:4180-4191.

55. Wada T, Ishiwata K, Koseki H, Ishikura T, Ugajin T, Ohnuma N, Obata K, Ishikawa R, Yoshikawa S, Mukai K, Kawano Y, Minegishi Y, Yokozeki H,
Watanabe N, Karasuyama H: Selective ablation of basophils in mice reveals their nonredundant role in acquired immunity against ticks. J Clin Invest 2010, 120:2867-2875.

56. Dai SX, Zhang AD, Huang JF: Evolution, expansion and expression of the Kunitz/BPTI gene family associated with long-term blood feeding in Ixodes scapularis. BMC Evol Biol 2012, 12:4.

57. Anatriello E, Ribeiro J, de Miranda-Santos I, Brandao L, Anderson J, Valenzuela J, Maruyama S, Silva J, Ferreira B: An insight into the sialotranscriptome of the brown dog tick, Rhipicephalus sanguineus. BMC Genomics 2010, 11:450.

58. Karim S, Troiano E, Mather TN: Functional genomics tool: gene silencing in Ixodes scapularis eggs and nymphs by electroporated dsRNA. BMC Biotechnol 2010, 10:1.

59. Ribeiro JM, Anderson JM, Manoukis NC, Meng Z, Francischetti IM: A further insight into the sialome of the tropical bont tick, Amblyomma variegatum. BMC Genomics 2011, 12:136.

60. Francischetti IM, Anderson JM, Manoukis N, Pham VM, Ribeiro JM: An insight into the sialotranscriptome and proteome of the coarse bontlegged tick, Hyalomma marginatum rufipes. J Proteomics 2011 74:2892-2908

61. Schwarz A, von Reumont BM, Erhart J, Chagas AC, Ribeiro JMC, Kotsyfakis M: De novo Ixodes ricinus salivary gland transcriptome analysis using two next-generation sequencing methodologies. FASEB J 2013, 27:4745-4756.

62. Mans BJ, Andersen JF, Francischetti IM, Valenzuela JG, Schwan TG, Pham VM, Garfield MK, Hammer CH, Ribeiro JM: Comparative sialomics between hard and soft ticks: implications for the evolution of blood-feeding behavior. Insect Biochem Mol Biol 2008, 38:42-58.

63. Francischetti IMB, Mans BJ, Meng Z, Gudderra N, Veenstra TD, Pham VM Ribeiro JMC: An insight into the sialome of the soft tick, Ornithodorus parkeri. Insect Biochem Mol Biol 2008, 38:1-21.

64. Francischetti IMB, Meng Z, Mans BJ, Gudderra N, Hall M, Veenstra TD, Pham VM, Kotsyfakis M, Ribeiro JMC: An insight into the salivary transcriptome and proteome of the soft tick and vector of epizootic bovine abortion, Ornithodoros coriaceus. J Proteomics 2008, 71:493-512.

65. Wang $Y$, Zhu S: The defensin gene family expansion in the tick Ixodes scapularis. Dev Comp Immunol 2011, 35:1128-1134.

66. Rego RO, Kovár V, Kopácek P, Weise C, Man P, Sauman I, Grubhoffer L: The tick plasma lectin, Dorin $M$, is a fibrinogen-related molecule. Insect Biochem Mol Biol 2006, 36:291-299.

67. Schwarz A, Valdés JJ, Kotsyfakis M: The role of cystatins in tick physiology and blood feeding. Ticks Tick Borne Dis 2012, 3:117-127.

68. Rodriguez-Valle M, Moolhuijzen P, Piper EK, Weiss O, Vance M, Bellgard M, Lew-Tabor A: Rhipicephalus microplus lipocalins (LRMs): genomic identification and analysis of the bovine immune response using in silico predicted $B$ and T cell epitopes. Int J Parasitol 2013, 43:739-752.

69. Mans BJ, Venter JD, Vrey PJ, Louw Al, Neitz AW: Identification of putative proteins involved in granule biogenesis of tick salivary glands. Electrophoresis 2001, 22:1739-1746.

70. Mans BJ, Louw Al, Neitz AW: The major tick salivary gland proteins and toxins from the soft tick, Ornithodoros savignyi, are part of the tick Lipocalin family: implications for the origins of tick toxicoses. Mol Biol Evol 2003, 20:1158-1167.

71. Mans BJ, Ribeiro JM: Function, mechanism and evolution of the moubatin-clade of soft tick lipocalins. Insect Biochem Mol Biol 2008, 38:841-852

72. Neitz AW, Howell CJ, Potgieter DJ, Bezuidenhout JD: Proteins and free amino acids in the salivary secretion and haemolymph of the tick Amblyomma hebraeum. Onderstepoort J Vet Res 1978, 45:235-240.

73. Bowman AS, Gengler CL, Surdick MR, Zhu K, Essenberg RC, Sauer JR, Dillwith JW: A novel phospholipase A2 activity in saliva of the lone star tick, Amblyomma americanum (L.). Exp Parasitol 1997, 87:121-132.

74. Louw E, van der Merwe NA, Neitz AWH, Maritz-Olivier C: Evolution of the tissue factor pathway inhibitor-like Kunitz domain-containing protein family in Rhipicephalus microplus. Int J Parasitol 2013, 43:81-94.

75. Valdés JJ, Schwarz A, Cabeza de Vaca I, Calvo E, Pedra JHF, Guallar V, Kotsyfakis M: Tryptogalinin is a tick Kunitz serine protease inhibitor with a unique intrinsic disorder. PLoS One 2013, 8:e62562.

76. Francischetti IM, Mather TN, Ribeiro JM: Cloning of a salivary gland metalloprotease and characterization of gelatinase and fibrin(ogen)lytic activities in the saliva of the Lyme disease tick vector Ixodes scapularis. Biochem Biophys Res Commun 2003, 305:869-875. 
77. Ribeiro JM, Alarcon-Chaidez F, Francischetti IM, Mans BJ, Mather TN, Valenzuela JG, Wikel SK: An annotated catalog of salivary gland transcripts from Ixodes scapularis ticks. Insect Biochem Mol Biol 2006, 36:111-129.

78. Wong ES, Papenfuss AT, Whittington CM, Warren WC, Belov K: A limited role for gene duplications in the evolution of platypus venom. Mol Biol Evol 2012, 29:167-177.

79. Kunitz $M$, Northrop $\mathrm{JH}$ : Isolation from beef pancreas of crystalline trypsinogen, trypsin, a trypsin inhibitor, and an inhibitor-trypsin compound. J Gen Physiol 1936, 19:991-1007.

80. Schwarz A, Cabezas-Cruz A, Kopecký J, Valdés JJ: Understanding the evolutionary structural variability and target specificity of tick salivary Kunitz peptides using next generation transcriptome data. BMC Evol Biol 2014, 14:4.

81. Mans BJ, Neitz AW: Adaptation of ticks to a blood-feeding environment: evolution from a functional perspective. Insect Biochem Mol Biol 2004, 34:1-17.

82. Chen ZY, Hu YT, Yang WS, He YW, Feng J, Wang B, Zhao RM, Ding JP, Cao ZJ, Li WX, Wu YL: Hg1, novel peptide inhibitor specific for Kv1.3 channels from first scorpion Kunitz-type potassium channel toxin family. J Biol Chem 2012, 287:13813-13821.

83. Peng $K$, Lin $Y$, Liang SP: Nuclear magnetic resonance studies on huwentoxin-XI from the Chinese bird spider Ornithoctonus huwena: $15 \mathrm{~N}$ labeling and sequence-specific $1 \mathrm{H}, 15 \mathrm{~N}$ nuclear magnetic resonance assignments. Acta Biochim Biophys Sin 2006, 38:457-466.

84. Selisko B, Garcia C, Becerril B, Delepierre M, Possani LD: An insect-specific toxin from Centruroides noxius Hoffmann. cDNA, primary structure, three-dimensional model and electrostatic surface potentials in comparison with other toxin variants. Eur J Biochem 1996, 242:235-242

85. Paesen GC, Siebold C, Dallas ML, Peers C, Harlos K, Nuttall PA, Nunn MA, Stuart DI, Esnouf RM: An ion-channel modulator from the saliva of the brown ear tick has a highly modified kunitz/BPTI structure. J Mol Biol 2009, 389:734-747

86. Jordan SP, Waxman L, Smith DE, Vlasuk GP: Tick anticoagulant peptide: kinetic analysis of the recombinant inhibitor with blood coagulation factor Xa. Biochemistry 1990, 29:11095-11100.

87. van de Locht A, Stubbs MT, Bode W, Friedrich T, Bollschweiler C, Höffken W, Huber R: The ornithodorin-thrombin crystal structure, a key to the TAP enigma? EMBO J 1996, 15:6011-6017.

88. Soares TS, Watanabe RM, Tanaka-Azevedo AM, Torquato RJ, Lu S, Figueiredo AC, Pereira PJ, Tanaka AS: Expression and functional characterization of boophilin, a thrombin inhibitor from Rhipicephalus (Boophilus) microplus midgut. Vet Parasitol 2012, 187:521-528.

89. Paesen GC, Siebold C, Harlos K, Peacey MF, Nuttall PA, Stuart DI: A tick protein with a modified kunitz fold inhibits human tryptase. $J \mathrm{Mol} B$ Biol 2007, 368:1172-1186.

90. Chen J, Deng M, He Q, Meng E, Jiang L, Liao Z, Rong M, Liang S: Molecular diversity and evolution of cystine knot toxins of the tarantula Chilobrachys jingzhao. Cell Mol Life Sci 2008, 65:2431-2444.

91. Richards R, St Pierre L, Trabi M, Johnson LA, de Jersey J, Masci PP, Lavin MF: Cloning and characterisation of novel cystatins from elapid snake venom glands. Biochimie 2011, 93:659-668.

92. Veiga $A B$, Ribeiro JM, Guimarães JA, Francischetti IM: A catalog for the transcripts from the venomous structures of the caterpillar Lonomia obliqua: identification of the proteins potentially involved in the coagulation disorder and hemorrhagic syndrome. Gene 2005, $1: 11-27$.

93. Evans HJ, Barrett AJ: A cystatin-like cysteine proteinase inhibitor from venom of the African puff adder (Bitis arietans). Biochem J 1987, 246:795-797.

94. Imamura S, Konnai S, Yamada S, Parizi LF, Githaka N, Vaz I, Murata S, Ohashi K: Identification and partial characterization of a gut Rhipicephalus appendiculatus cystatin. Ticks Tick Borne Dis 2013, 4:138-144.

95. Zhou J, Ueda M, Umemiya R, Battsetseg B, Boldbaatar D, Xuan X, Fujisaki K A secreted cystatin from the tick Haemaphysalis longicornis and its distinct expression patterns in relation to innate immunity. Insect Biochem Mol Biol 2006, 36:527-535.

96. Ibelli AR, Hermance M, Kim T, Gonzalez C, Mulenga A: Bioinformatics and expression analyses of the Ixodes scapularis tick cystatin family. Exp Appl Acarol 2013, 60:41-53.

97. Gachomo EW, Jimenez-Lopez JC, Kayodé AP, Baba-Moussa L, Kotchoni SO: Structural characterization of plant defensin protein superfamily. Mol Biol Rep 2012, 39:4461-4469.
98. van Dijk A, Veldhuizen EJ, Haagsman HP: Avian defensins. Vet Immunol Immunopathol 2008, 124:1-18.

99. Zhu S, Peigneur S, Gao B, Umetsu Y, Ohki S, Tytgat J: Experimental conversion of a defensin into a neurotoxin: implications for origin of toxic function. Mol Biol Evol 2014, 31:546-559.

100. Jarczak J, Kościuczuk EM, Lisowski P, Strzałkowska N, Jóźwik A, Horbańczuk J, Krzyżewski J, Zwierzchowski L, Bagnicka E: Defensins: natural component of human innate immunity. Hum Immunol 2013, 74:1069-1079.

101. Menendez A, Finlay BB: Defensins in the immunology of bacterial infections. Curr Opin Immunol 2007, 19:385-391.

102. Zhu S, Gao B, Tytgat J: Phylogenetic distribution, functional epitopes and evolution of the CSalphabeta superfamily. Cell Mol Life Sci 2005 62:2257-2269

103. Zhu S, Tytgat J: The scorpine family of defensins: gene structure, alternative polyadenylation and fold recognition. Cell Mol Life Sci 2004 61:1751-1763.

104. Feng J, Yu C, Wang M, Li Z, Wu Y, Cao Z, Li W, He X, Han S: Expression and characterization of a novel scorpine-like peptide Ev37, from the scorpion Euscorpiops validus. Protein Expr Purif 2013, 88:127-133.

105. Oguiura N, Boni-Mitake M, Affonso R, Zhang G: In vitro antibacterial and hemolytic activities of crotamine, a small basic myotoxin from rattlesnake Crotalus durissus. J Antibiot (Tokyo) 2011, 64:327-331.

106. Dalla VL, Benato F, Maistro S, Quinzani S, Alibardi L: Bioinformatic and molecular characterization of beta-defensins-like peptides isolated from the green lizard Anolis carolinensis. Dev Comp Immunol 2012, 36:222-229.

107. Whittington CM, Papenfuss AT, Bansal P, Torres AM, Wong ES, Deakin JE, Graves T, Alsop A, Schatzkamer K, Kremitzki C, Ponting CP, Temple-Smith P, Warren WC, Kuchel PW, Belov K: Defensins and the convergent evolution of platypus and reptile venom genes. Genome Res 2008, 18:986-994.

108. Zhao H, Kong Y, Wang H, Yan T, Feng F, Bian J, Yang Y, Yu H: A defensin-like antimicrobial peptide from the venoms of spider, Ornithoctonus hainana. J Pept Sci 2011, 17:540-544.

109. Yamane ES, Bizerra FC, Oliveira EB, Moreira JT, Rajabi M, Nunes GL, de Souza AO, da Silva ID, Yamane T, Karpel RL, Silva PI Jr, Hayashi MA: Unraveling the antifungal activity of a South American rattlesnake toxin crotamine. Biochimie 2013, 95:231-240.

110. Ceraul SM, Dreher-Lesnick SM, Gillespie JJ, Rahman MS, Azad AF: New tick defensin isoform and antimicrobial gene expression in response to Rickettsia montanensis challenge. Infect Immun 2007 75:1973-1983.

111. Chrudimská T, Slaninová J, Rudenko N, Růžek D, Grubhoffer L: Functional characterization of two defensin isoforms of the hard tick Ixodes ricinus. Parasit Vectors 2011, 4:63.

112. Zhou J, Liao M, Ueda M, Gong H, Xuan X, Fujisaki K: Sequence characterization and expression patterns of two defensin-like antimicrobial peptides from the tick Haemaphysalis longicornis. Peptides 2007, 28:1304-1310.

113. Chrudimská T, Chrudimsky' T, Golovchenko M, Rudenko N, Grubhoffer L: New defensins from hard and soft ticks: similarities, differences, and phylogenetic analyses. Vet Parasitol 2010, 167:298-303.

114. Lu X, Che Q, Lv Y, Wang M, Lu Z, Feng F, Liu J, Yu H: A novel defensin-like peptide from salivary glands of the hard tick, Haemaphysalis longicornis. Protein Sci 2010, 19:392-397.

115. Fogaça AC, Almeida IC, Eberlin MN, Tanaka AS, Bulet P, Daffre S: Ixodidin, a novel antimicrobial peptide from the hemocytes of the cattle tick Boophilus microplus with inhibitory activity against serine proteinases. Peptides 2006, 27:667-674.

116. Zhang $H$, Zhang W, Wang $X$, Zhou Y, Wang N, Zhou J: Identification of a cysteine-rich antimicrobial peptide from salivary glands of the tick Rhipicephalus haemaphysaloides. Peptides 2011, 32:441-446.

117. Froy O, Gurevitz M: Membrane potential modulators: a thread of scarlet from plants to humans. FASEB J 1998, 12:1793-1796.

118. Duda TF, Palumbi SR: Molecular genetics of ecological diversification: duplication and rapid evolution of toxin genes of the venomous gastropod Conus. Proc Natl Acad Sci U S A 1998, 96:6820-6823.

119. Terlau H, Olivera BM: Conus venoms: a rich source of novel ion channel-targeted peptides. Physiol Rev 2004, 84:41-68.

120. Carrijo-Carvalho LC, Maria DA, Ventura JS, Morais KL, Melo RL, Rodrigues CJ, Chudzinski-Tavassi AM: A lipocalin-derived Peptide modulating fibroblasts and extracellular matrix proteins. J Toxicol 2012, 2012:325250 
121. Fry BG, Scheib $H$, de L M Junqueira de Azevedo I, Silva DA, Casewell NR: Novel transcripts in the maxillary venom glands of advanced snakes. Toxicon 2012, 59:696-708.

122. Keller PM, Waxman L, Arnold BA, Schultz LD, Condra C, Connolly TM: Cloning of the cDNA and expression of moubatin, an inhibitor of platelet aggregation. J Biol Chem 1993, 268:5450-5456.

123. Nunn MA, Sharma A, Paesen GC, Adamson S, Lissina O, Willis AC, Nuttall PA: Complement inhibitor of $\mathrm{C} 5$ activation from the soft tick Ornithodoros moubata. J Immunol 2005, 174:2084-2091.

124. Roversi P, Ryffel B, Togbe D, Maillet I, Teixeira M, Ahmat N, Paesen GC, Lissina O, Boland W, Ploss K, Caesar JJ, Leonhartsberger S, Lea SM, Nunn MA: Bifunctional lipocalin ameliorates murine immune complex-induced acute lung injury. J Biol Chem 2013, 288:18789-18802.

125. Alvarez FMP, Zannin M, Chudzinski-Tavassi AM: New insight into the mechanism of Lonomia obliqua envenoming: toxin involvement and molecular approach. Pathophysiol Haemost Thromb 2010, 37:1-16.

126. Weckesser S, Hilger C, Lentz D, Jakob T: Anaphylactic reactions to bites of the pigeon tick Argas reflexus. Eur J Dermatol 2010, 20:244-245.

127. Hilger C, Bessot JC, Hutt N, Grigioni F, De Blay F, Pauli G, Hentges F: IgE-mediated anaphylaxis caused by bites of the pigeon tick Argas reflexus: cloning and expression of the major allergen Arg r 1. J Allergy Clin Immunol 2005, 115:617-622.

128. Mans BJ: Tick histamine-binding proteins and related lipocalins: potential as therapeutic agents. Curr Opin Investig Drugs 2005, 6:1131-1135.

129. Mans BJ, Ribeiro JM: A novel clade of cysteinyl leukotriene scavengers in soft ticks. Insect Biochem Mol Biol 2008, 38:862-870.

130. Burke JE, Dennis EA: Phospholipase A2 biochemistry. Cardiovasc Drugs Ther 2009, 23:49-59.

131. Schaloske RH, Dennis EA: The phospholipase A2 superfamily and its group numbering system. Biochim Biophys Acta 2006, 1761:1246-1259.

132. Chang HC, Tsai TS, Tsai IH: Functional proteomic approach to discover geographic variations of king cobra venoms from Southeast Asia and China. J Proteomics 2013, 89:141-153.

133. Harris JB, Scott-Davey T: Secreted phospholipases A2 of snake venoms: effects on the peripheral neuromuscular system with comments on the role of phospholipases $\mathrm{A} 2$ in disorders of the CNS and their uses in industry. Toxins (Basel) 2013, 5:2533-2571.

134. Zhu K, Bowman AS, Dillwith JW, Sauer JR: Phospholipase $A_{2}$ activity in salivary glands and saliva of the lone star tick (Acari: Ixodidae) during tick feeding. J Med Entomol 1998, 35:500-504.

135. Zhu K, Sauer JR, Bowman AS, Dillwith JW: Identification and characterization of anticoagulant activities in the saliva of the lone star tick, Amblyomma americanum (L.). J Parasitol 1997, 83:38-43.

136. Zeidner N, Ullmann A, Sackal C, Dolan M, Dietrich G, Piesman J, Champagne D: A borreliacidal factor in Amblyomma americanum saliva is associated with phospholipase A2 activity. Exp Parasitol 2009, 121:370-375

137. Sampaio SC, Hyslop S, Fontes MR, Prado-Franceschi J, Zambelli VO, Magro AJ, Brigatte P, Gutierrez VP, Cury Y: Crotoxin: novel activities for a classic beta-neurotoxin. Toxicon 2010, 55:1045-1060.

138. Noetzel C, Chandra V, Perbandt M, Rajashankar K, Singh T, Aleksiev B, Kalkura N, Genov N, Betzel C: Enzymatic activity and inhibition of the neurotoxic complex vipoxin from the venom of Vipera ammodytes meridionalis. Z Naturforsch C 2002, 57:1078-1083.

139. Sousa PC, Brito TS, Freire DS, Ximenes RM, Magalhães PJ, Monteiro HS, Alves RS, Martins AM, Toyama DO, Toyama MH: Vasoconstrictor effect of Africanized honeybee (Apis mellifera L.) venom on rat aorta. J Venom Anim Toxins Ind Trop Dis 2013, 19:24.

140. Valdivia HH, Kirby MS, Lederer WJ, Coronado R: Scorpion toxins targeted against the sarcoplasmic reticulum $\mathrm{Ca}(2+)$-release channel of skeletal and cardiac muscle. Proc Natl Acad Sci U S A 1992, 89:12185-12189.

141. Vasta GR, Nita-Lazar M, Giomarelli B, Ahmed H, Du S, Cammarata M, Parrinello N, Bianchet MA, Amzel LM: Structural and functional diversity of the lectin repertoire in teleost fish: relevance to innate and adaptive immunity. Dev Comp Immunol 2011, 35:1388-1399.

142. Herrera C, Rucavado A, Warrell DA, Gutiérrez JM: Systemic effects induced by the venom of the snake Bothrops caribbaeus in a murine model. Toxicon 2013, 1:19-31.

143. Momic T, Cohen G, Reich R, Arlinghaus FT, Eble JA, Marcinkiewicz C Lazarovici P: Vixapatin (VP12), a c-type lectin-protein from Vipera xantina palestinae venom: characterization as a novel anti-angiogenic compound. Toxins (Basel) 2012, 4:862-877.
144. Magalhães GS, Junqueira-de-Azevedo IL, Lopes-Ferreira M, Lorenzini DM, Ho PL, Moura-da-Silva AM: Transcriptome analysis of expressed sequence tags from the venom glands of the fish Thalassophryne nattereri. Biochimie 2006, 88:693-699.

145. Kopácek P, Hajdusek O, Buresová V, Daffre S: Tick innate immunity. Adv Exp Med Biol 2010, 708:137-162.

146. Hajdušek O, Síma R, Ayllón N, Jalovecká M, Perner J, de la Fuente J, Kopáček P: Interaction of the tick immune system with transmitted pathogens. Front Cell Infect Microbiol 2013, 16:26.

147. Bautista-Garfias CR, Martínez-Cruz MA, Córdoba-Alva F: Lectin activity from the cattle tick (Boophilus microplus) saliva. Rev Latinoam Microbiol 1997, 39:83-89.

148. Rego RO, Hajdusek O, Kovár V, Kopácek P, Grubhoffer L, Hypsa V: Molecular cloning and comparative analysis of fibrinogen-related proteins from the soft tick Ornithodoros moubata and the hard tick Ixodes ricinus. Insect Biochem Mol Biol 2005, 35:991-1004.

149. OmPraba G, Chapeaurouge A, Doley R, Devi KR, Padmanaban P, Venkatraman C, Velmurugan D, Lin Q, Kini RM: Identification of a novel family of snake venom proteins Veficolins from Cerberus rynchops using a venom gland transcriptomics and proteomics approach. J Proteome Res 2010, 9:1882-1893.

150. Jágr M, Eckhardt A, Pataridis S, Broukal Z, Dušková J, Mikšík I: Proteomics of human teeth and saliva. Physio/ Res 2014, 63:S141-S154.

151. Loo JA, Yan W, Ramachandran P, Wong DT: Comparative human salivary and plasma proteomes. J Dent Res 2010, 89:1016-1023.

152. Walter DE, Proctor HC: Feeding behaviour and phylogeny: observations on early derivative Acari. Exp Appl Acarol 1998, 22:39-50.

153. Steen NA, Barker SC, Alewood PF: Proteins in the saliva of the Ixodida (ticks): pharmacological features and biological significance. Toxicon 2006, 47:1-20.

154. Grimaldi D, Engel MS: Evolution of the Insects. UK: Cambridge University Press; 2005.

155. Ovchinnikov S, Masta SE: Pseudoscorpion mitochondria show rearranged genes and genome-wide reductions of RNA gene sizes and inferred structures, yet typical nucleotide composition bias. BMC Evol Bio/ 2012 12:12-31.

156. Murienne J, Harvey MS, Giribet G: First molecular phylogeny of the major clades of Pseudoscorpiones (Arthropoda: Chelicerata). Mol Phylogenet Evol 2008, 49:170-184.

157. Mans BJ, de Klerk DG, Pienaar R, Latif AA: The host preferences of Nuttalliella namaqua (Ixodoidea: Nuttalliellidae): a generalist approach to surviving multiple host-switches. Exp Appl Acarol 2014, 62:233-240.

158. Randolph SE: Tick ecology: processes and patterns behind the epidemiological risk posed by ixodid ticks as vectors. Parasitol 2004 129:S37-S65.

159. Goddard J: Observations on questing activity of adult Ixodes brunneus Koch (Acari: Ixodidae) in Mississippi. J Parasitol 2013, 99:346-349.

160. Bartosik K, Wiśniowski Ł, Buczek A: Questing behavior of Dermacentor reticulatus adults (Acari: Amblyommidae) during diurnal activity periods in eastern Poland. J Med Entomol 2012, 49:859-864.

161. Leonovich SA: The main evolutionary trends in sensory organs and questing behavior of parasitiform ticks and mites (Parasitiformes). Parazitol 2013, 47:204-211.

162. Foelix RF, Chu-Wang IW, Beck L: Fine structure of tarsal sensory organs in the whip spider Admetus pumilio (Amblypygi, Arachnida). Tissue Cell 1975, 7:331-346

163. Kelley LA, Sternberg MJE: Protein structure prediction on the Web: a case study using the Phyre server. Nat Protocols 2009, 4:363-371.

164. Li X, Jacobson MP, Zhu K, Zhao S, Friesner RA: Assignment of polar states for protein amino acid residues using an interaction cluster decomposition algorithm and its application to high resolution protein structure modeling. Proteins Struct Funct Bioinformatics 2007, 66:824-837.

doi:10.1186/1742-9994-11-47

Cite this article as: Cabezas-Cruz and Valdés: Are ticks venomous animals?. Frontiers in Zoology 2014 11:47. 